\title{
Close contacts involving germanium and tin in crystal structures: experimental evidence of tetrel bonds
}

\author{
Patrick Scilabra ${ }^{1}$ - Vijith Kumar ${ }^{1}$ - Maurizio Ursini ${ }^{1} \cdot$ Giuseppe Resnati $^{1}$ (D)
}

Received: 9 November 2017 / Accepted: 14 December 2017 / Published online: 8 January 2018

(C) The Author(s) 2018. This article is an open access publication

\begin{abstract}
Modeling indicates the presence of a region of low electronic density (a " $\sigma$-hole") on group 14 elements, and this offers an explanation for the ability of these elements to act as electrophilic sites and to form attractive interactions with nucleophiles. While many papers have described theoretical investigations of interactions involving carbon and silicon, such investigations of the heavier group 14 elements are relatively scarce. The purpose of this review is to rectify, to some extent, the current lack of experimental data on interactions formed by germanium and tin with nucleophiles. A survey of crystal structures in the Cambridge Structural Database is reported. This survey reveals that close contacts between Ge or Sn and lone-pair-possessing atoms are quite common, they can be either intra- or intermolecular contacts, and they are usually oriented along the extension of the covalent bond formed by the tetrel with the most electron-withdrawing substituent. Several examples are discussed in which germanium and tin atoms bear four carbon residues or in which halogen, oxygen, sulfur, or nitrogen substituents replace one, two, or three of those carbon residues. These close contacts are assumed to be the result of attractive interactions between the involved atoms and afford experimental evidence of the ability of germanium and tin to act as electrophilic sites, namely tetrel bond (TB) donors. This ability can govern the conformations and the packing of organic derivatives in the solid state. TBs can therefore be considered a promising and robust tool for crystal engineering.
\end{abstract}

Keywords Tetrel bond $\cdot$ Crystal engineering $\cdot \sigma$-Hole interactions $\cdot$ Supramolecular interactions

\section{Introduction}

A comprehensive knowledge of the various interactions (i.e., weak bonds) that a molecule can participate in is a fundamental prerequisite for controlling and designing the conformation and the packing that the molecule adopts in a crystal. Interatomic distances that are slightly less than the sum of the van der Waals radii of the atoms involved (hereafter termed "close contacts") are usually (but not always) the result of attractive interactions between the involved atoms. Observing the systematic occurrence of close contacts in crystalline solids can thus provide great insights into the attractive interactions that atoms and molecular moieties can participate

This paper belongs to Topical Collection P. Politzer 80th Birthday Festschrift

Giuseppe Resnati

giuseppe.resnati@polimi.it

1 NFMLab - D.C.M.I.C. "Giulio Natta”, Politecnico di Milano, Via L. Mancinelli 7, 20131 Milan, Italy in. Close contacts play a crucial role in the properties of matter, especially condensed phases, and knowledge and control of these contacts enables the functional properties of materials - synthetic and natural — to be designed and optimized [1-3].

Hydrogen bonds (HBs) are by far the most frequently occurring and widely studied type of interaction $[4,5]$; other weak interactions that have traditionally received attention include $\pi-\pi$ [6], cation $-\pi$ [7], anion- $\pi$ [8], and aurophilic [9] bonds. $\sigma$-Hole interactions [10-12] represent a relatively recent entry into the canon of weak bonds [13-15], but following the seminal papers of P. Politzer et al. [16, 17], these interactions rapidly became popular targets for studies in this field $[15,18-20]$. A covalently bonded atom characteristically has a region of low electron density, known as the " $\sigma$-hole," which is usually located along the extension of the covalent bond but on the opposite side of the atom to the bond. The electrostatic potential in this region is frequently positive and $\sigma$-hole bonding is the result of an attractive interaction between this positive region (an electrophilic site, the donor site in the interaction) and a negative site (a nucleophilic site, the 
acceptor site in the interaction, e.g., a lone-pair-possessing atom or an anion). In general, the largest number of $\sigma$-holes that an atom can have (which may drive the formation of attractive interactions) is equal to the number of the covalent bonds it is involved in. The more electron-withdrawing the group(s) covalently bound to a given atom is/are, the more extended and more positive the $\sigma$-hole(s) opposite to the bond(s) is/are [21], and the stronger and shorter the resulting $\sigma$-hole interaction(s) is/are. A distinctive feature of $\sigma$-hole interactions is their directionality, a consequence of the rather localized nature of the region(s) of positive electrostatic potential. In an $\mathrm{R}-\mathrm{A} \cdots \mathrm{B}$ interaction, where $\mathrm{A}$ is the atom with the positive $\sigma$-hole potential and $\mathrm{B}$ is the nucleophile, the angle $\mathrm{R}-\mathrm{A} \cdots \mathrm{B}$ is generally between $155^{\circ}$ and $180^{\circ}$.

Experimental evidence and theoretical calculations consistently show that most of the elements in groups 14-18 of the periodic table form $\sigma$-hole bonds. A growing consensus is emerging among chemists that these interactions should be named according to the group of the periodic table that the electrophilic atom belongs to [22, 23]. Halogen bonds (XBs) $[10,24]$, namely interactions where an atom of a group 17 element is the electrophilic site, represent the best known subset of $\sigma$-hole interactions. Chalcogen bonds (CBs) have been studied in silico [25, 26] and in the solid [27], liquid [28], and gas [29] phases. Pnictogen bonds (PBs) have received much attention in studies performed in silico [30] and in the solid [31]; and the aerogen bond $(\mathrm{AB})$ is the most recently discovered subset of $\sigma$-hole interactions [32].

The tetrel bond (TB), namely an interaction in which a group 14 element is the electrophile, has received a great deal of attention, probably due to the scale of its influence in chemistry, e.g., its possible role in $\mathrm{S}_{\mathrm{N}} 2$ reactions and hydrophobic interactions $[13,33]$. The first convincing evidence of the ability of carbon to attractively interact with lone-pairpossessing atoms was reported more than forty years ago. In 1975, Johnson et al. calculated that the arrangement of the water-carbon dioxide dimer in which there is close $\mathrm{C} \cdots \mathrm{O}$ contact is more stable than the arrangement in which there is close $\mathrm{H} \cdots \mathrm{O}$ contact [34]. In 1984, Klemperer et al. confirmed, via microwave spectral analysis, that the equilibrium geometry of the adduct features a tetrel bond, i.e., that the tetrelbonded $\mathrm{O}_{2} \mathrm{C} \cdots \mathrm{OH}_{2}$ geometry is preferred to the hydrogenbonded $\mathrm{HO}-\mathrm{H} \cdots \mathrm{O}=\mathrm{CO}$ geometry [35]. During the $1980 \mathrm{~s}$, tetrel bonding was shown to be more important than hydrogen bonding for driving the formation of other lowest-energy complexes formed by carbon dioxide, for instance those with $\mathrm{HBr}$ [36] and HCN [37]. Most papers on the ability of tetrels to function as electrophiles describe theoretical investigations of interactions involving carbon [38] and silicon [39-41], whereas investigations of the heavier group 14 elements are far less frequent [42]. Experimental studies of TBs are quite limited $[29,43-45]$ and, to the best of our knowledge, they have never focused on interactions involving germanium or tin. We therefore decided to analyze structures in the Cambridge Structural Database (CSD) in order to assess whether organic derivatives of these two elements in crystalline solids show the presence of TBs. We looked for systems in which germanium and tin form close contacts with nucleophilic sites. Since directionality is a key characteristic of $\sigma$-hole interactions, particular attention was paid in this survey to the geometrical features of the observed close contacts, and a linear close contact was considered to be a TB.

In this paper, we discuss a selected number of crystalline structures of organic derivatives of germanium and tin in which these elements form TBs, i.e., close linear contacts with lone-pair-possessing heteroatoms. Structurally simple and poorly functionalized molecular systems are preferentially analyzed, as the $\mathrm{Ge} / \mathrm{Sn} \cdots$ nucleophile interactions that occur in these systems are more likely to be a straightforward product of the features of the two sites involved (contributions from other parts of the molecule(s) are likely to be insignificant). Wider coverage of organic Ge and Sn derivatives that present TBs in the solid is given in the works cited in this review. The interaction distances are analyzed based on the normalized

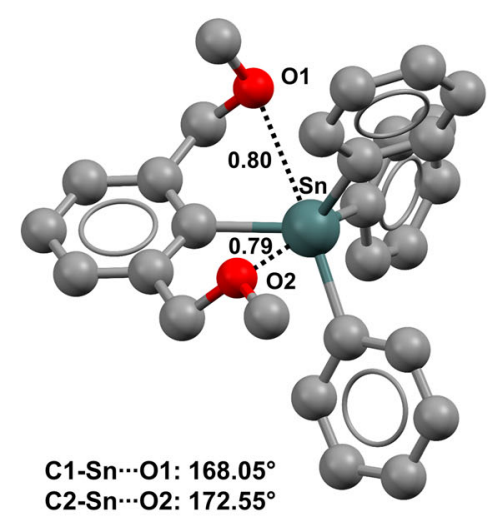

Fig. 1 Ball and stick representations (Mercury 3.9) of (2,6bis(methoxymethyl)phenyl)triphenyltin (MUBVOU, left) and (2,6bis(ethoxymethyl)phenyl)dichlorophenyltin (LIVHOO, right). TBs are

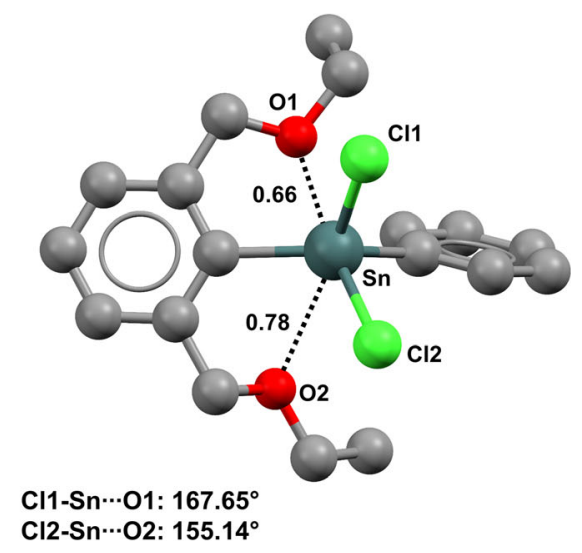

depicted as black dotted lines; hydrogens have been omitted for clarity. $\mathrm{Nc}$ values are shown close to the respective interactions. Color code: gray carbon, green chlorine, red oxygen, dark teal tin 
Fig. 2 Ball and stick

representations (Mercury 3.9) of methyl-tris( $(2-$

methoxymethyl)phenyl)germane (IMUTEP, top left), bromo-

tris( (2-

methoxymethyl)phenyl)germane (IMUTAL, top right), chloro$\operatorname{tris}((2-$

methoxymethyl)phenyl)germane (IMUSUE, bottom left), and fluoro-tris $((2-$

methoxymethyl)phenyl)germane (IMUSOY, bottom right). TBs are depicted as black dotted lines; hydrogens have been omitted for clarity. Nc values are shown close to the respective interactions. Color code: gray carbon, brown bromine, green chlorine, yellowish green fluorine, red oxygen, light teal germanium
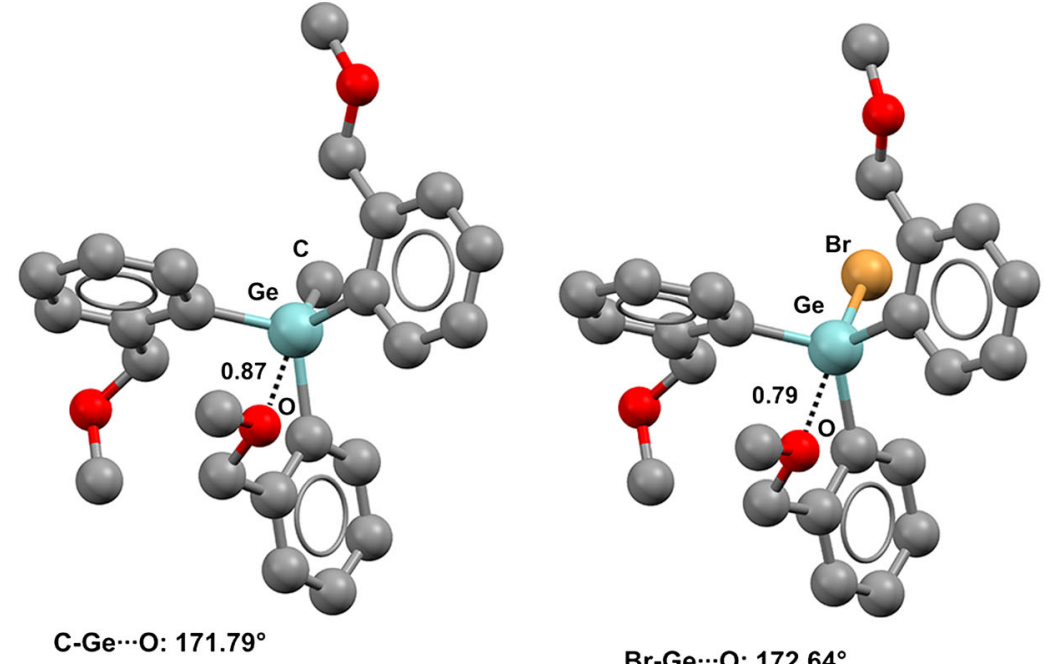

$\mathrm{Br}-\mathrm{Ge} \cdots \mathrm{O}: 172.64^{\circ}$

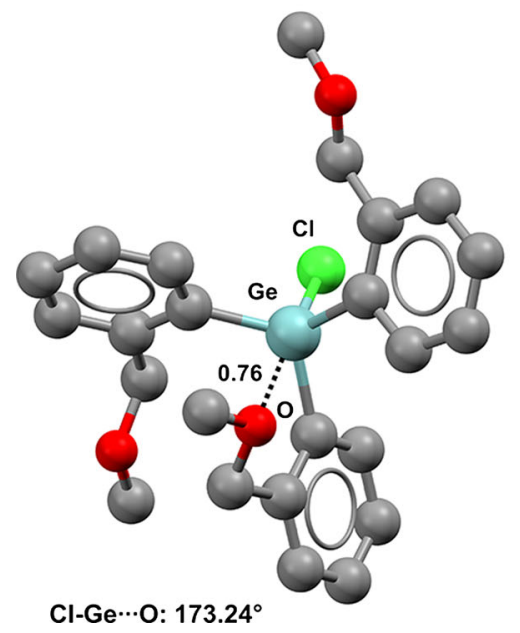

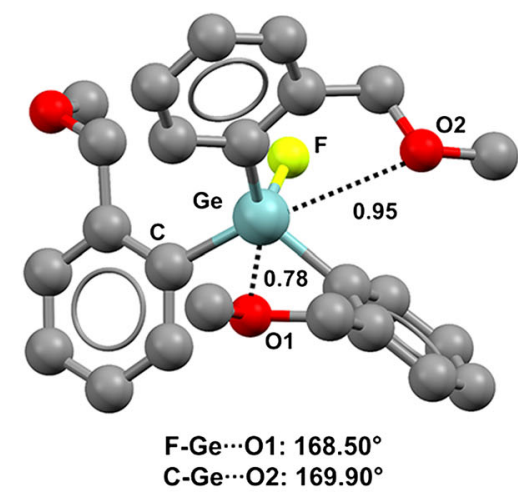

contact $(\mathrm{Nc})$, defined as the ratio between the experimentally observed separation of the interacting atoms and the sum of their respective van der Waals radii [46]. ${ }^{1}$ The use of Nc values allows linear comparisons between contacts involving different atoms. While the number of CSD structures in which $\mathrm{Ge} / \mathrm{Sn}^{\prime} \cdots$ nucleophile interactions are present is not large enough to enable definitive and detailed generalizations to be made, the CSD survey reported here shows that the formation of attractive interactions between organic Ge and Sn sites and a donor of electron density can become a determinant of structure in crystalline solids. Intra- and intermolecular TBs are observed, and they can affect the preferred conformation of a molecule and/or the network of intermolecular interactions in the crystal packing. Importantly, the cases collected here provide convincing experimental evidence that TBs tend to be more linear than PBs [31].

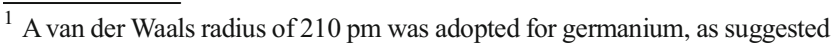
by Batsanov in [47].
}

\section{Oxygen atoms as TB acceptors}

The conformation adopted by (2,6-bis(methoxymethyl) phenyl)triphenyltin (refcode MUBVOU) in the crystal (Fig. 1, left) seems to be determined by two intramolecular $\mathrm{Sn} \cdots \mathrm{O}$ TBs [48]. One interaction distance is slightly shorter than the other, with the two Nc values being 0.76 and 0.78 . Shorter $\sigma$-hole interactions usually tend to be more linear; consistent with this characteristic, the two $\mathrm{C}-\mathrm{Sn} \cdots \mathrm{O}$ angles in the TBs mentioned above are $168.05^{\circ}$ and $172.55^{\circ}$, respectively. As discussed above, another common feature of $\sigma$-hole interactions is that the more electron-withdrawing the residue covalently bonded to the $\sigma$-hole donor site, the more positive the $\sigma$-hole, and the closer and stronger the interactions with incoming nucleophiles. Interestingly, in an analog of the compound discussed above wherein two of the phenyl rings are replaced with chlorine atoms, the two intramolecular TBs a r e $\mathrm{much}$ shorter; i.e., in (2,6bis(ethoxymethyl)phenyl)dichlorophenyltin (refcode 


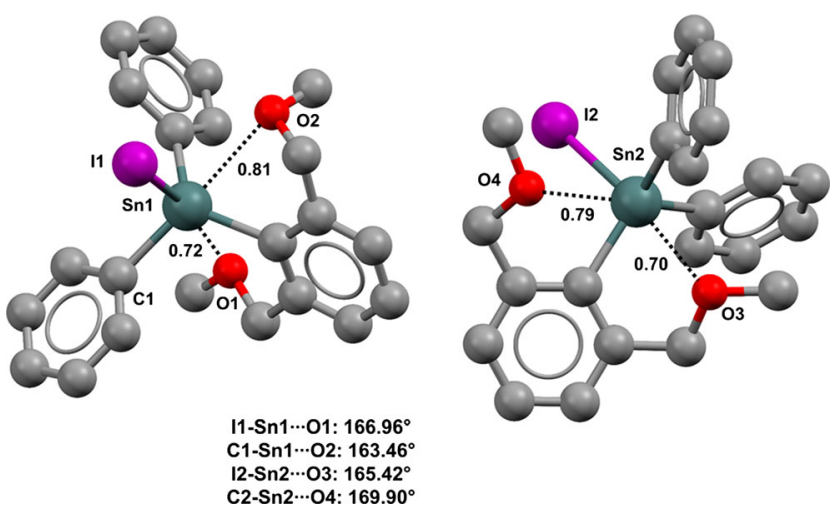

Fig. 3 Ball and stick representation (Mercury 3.9) of the two molecules of the unit cell of iodo(2,6-bis(methoxymethyl)phenyl)diphenyltin (RAKBOV). TBs are depicted as black dotted lines; hydrogen atoms have been omitted for clarity. Nc values are shown close to the respective interactions. Color code: gray carbon, red oxygen, purple iodine, dark teal tin

LIVHOO), the Nc values for the $\mathrm{Sn} \cdots \mathrm{O}$ TBs are 0.66 and 0.78

(Fig. 1, right) [49].

It is extensively documented that the propensity of a halogen atom to form XBs increases with its molecular weight [10], and that the heavier halogens usually form stronger and shorter XBs than the lighter ones, with both of these behaviors being independent of the XB acceptor. Similar trends are observed when elements of groups 16 and 15 form CBs and PBs, respectively. In all cases, this is probably due to the fact that within a group of the periodic table, the polarizability increases with the molecular weight of the element, and high polarizability favors an anisotropic distribution of the electron density around the atom and thus the strength of $\sigma$-hole interactions. It is no surprise [50] that methyl-tris ( $(2-$ methoxymethyl)phenyl)germane (refcode IMUTEP) shows only one $\mathrm{C}-\mathrm{Ge} \cdots \mathrm{O}$ contact, and that the corresponding $\mathrm{Nc}$ value $(0.87)$ is greater than the Nc values of the structurally similar tin derivatives MUBVOU and LIVHOO [51] (Fig. 2, top left).

Bromine is more electronegative than carbon, and the $\mathrm{Br}-$ $\mathrm{Ge} \cdots \mathrm{O}$ TB in bromo-tris((2-methoxymethyl)phenyl)germane (refcode IMUTAL) is shorter $(\mathrm{Nc}=0.79)$ than the $\mathrm{C}-\mathrm{Ge} \cdots \mathrm{O}$ in
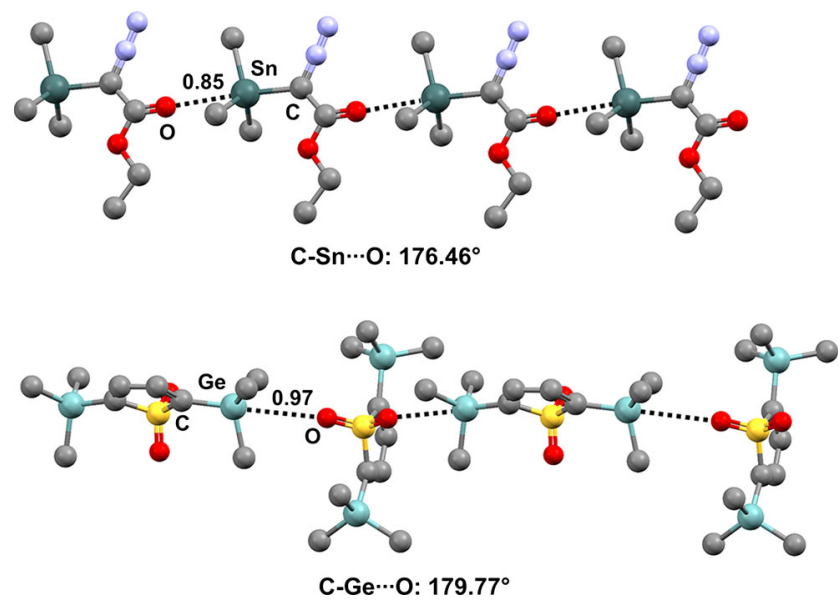

Fig. 5 Ball and stick representations (Mercury 3.9) of 1D chains generated by ethyl trimethyltin diazoacetate (SIWRAR, top) and 2,5bis(trimethylgermyl)thiophene-1,1-dioxide (QAHXIG, bottom). TBs are depicted as black dotted lines; hydrogen atoms have been omitted for clarity. Nc values are shown close to the respective interactions. Color code: gray carbon, red oxygen, light blue nitrogen, yellow sulfur, light teal germanium, dark teal tin

IMUTEP (Fig. 2, top right) [51]; chlorine is more electronegative than bromine, and the $\mathrm{Cl}-\mathrm{Ge} \cdots \mathrm{O}$ TB in chloro-tris $((2-$ methoxymethyl)phenyl)germane (refcode IMUSUE) is even shorter $(\mathrm{Nc}=0.76)$ (Fig. 2, bottom left) than the $\mathrm{Br}-\mathrm{Ge} \cdots \mathrm{O}$ TB. Also, in these three structures, the linearity of the TB is correlated with its length (the $\mathrm{C}-\mathrm{Ge} \cdots \mathrm{O}, \mathrm{Br}-\mathrm{Ge} \cdots \mathrm{O}$, and $\mathrm{Cl}-$ $\mathrm{Ge} \cdots \mathrm{O}$ angles are $171.79^{\circ}, 172.64^{\circ}$, and $173.24^{\circ}$, respectively). In fluoro-tris((2-methoxymethyl)phenyl)germane (refcode IMUSOY), a fluorine is substituted for the methyl of IMUTEP and the depletion of electron density at germanium becomes large enough that two TBs are present (Fig. 2, bottom right). Consistent with the relative electronegativities of fluorine and carbon, the $\mathrm{F}-\mathrm{Ge} \cdots \mathrm{O}$ interaction is closer and more directional than the $\mathrm{C}-\mathrm{Ge} \cdots \mathrm{O}$ interaction (the $\mathrm{Nc}$ values for the $\mathrm{Ge} \cdots \mathrm{O}$ separations are 0.78 and 0.95 , respectively). Also, the presence of a tin-bonded iodine atom can promote the formation of close contacts (Fig. 3). Two independent molecules are present in the unit cell of crystalline iodo(2,6bis(methoxymethyl)phenyl)diphenyltin (refcode RAKBOV),

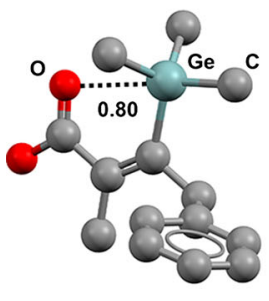

C-Ge $\cdots$ O: $175.00^{\circ}$

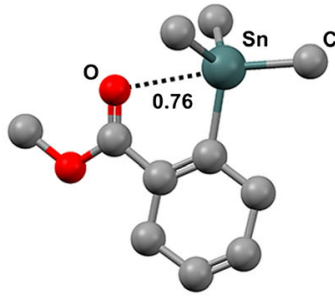

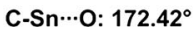

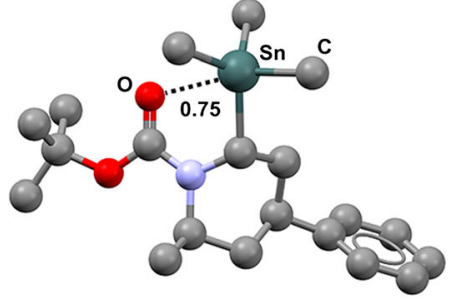

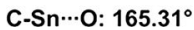

Fig. 4 Ball and stick representations (Mercury 3.9) of one of the two independent molecules in the unit cells of (Z)-2-methyl-4-phenyl-3(trimethylgermanyl)but-2-enoic acid (QIBDOV, left), (2-carbomethoxy1,4-cyclohexadien-1-yl)trimethyltin (KASYOS, middle), and trans- $N$ - $t$ butyloxycarbonyl-2-methyl-6-(trimethylstannyl)-4-phenyl)piperidine
(EABFES, right) derivatives. TBs are depicted as black dotted lines; hydrogen atoms have been omitted for clarity. Nc values are shown close to the respective interactions. Color code: gray carbon, red oxygen, light blue nitrogen, light teal germanium, dark teal tin 

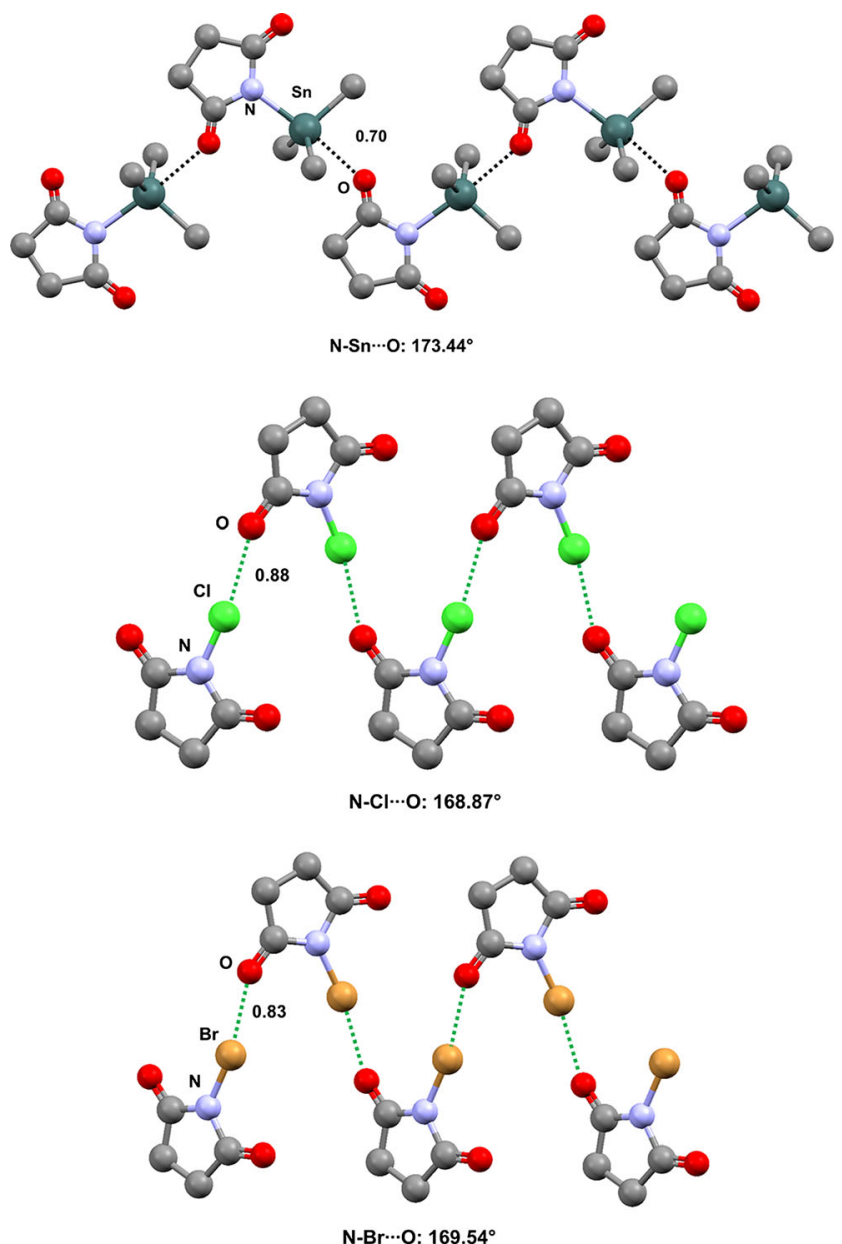

Fig. 6 Ball and stick representations (Mercury 3.9) of the 1D networks formed by $N$-triethylstannylsuccinimide (FUSZIC) due to $\mathrm{N}-\mathrm{Sn} \cdots \mathrm{O}$ TBs (top), by $\mathrm{N}$-chlorosuccinimide (CSUCIM) due to $\mathrm{N}-\mathrm{Cl} \cdots \mathrm{O}$ XBs (middle), and by $\mathrm{N}$-bromosuccinimide (NBSUCA) due to $\mathrm{N}-\mathrm{Br} \cdots \mathrm{O}$ XBs (bottom). The three methyl groups of the ethyl residues of $N$ triethylstannylsuccinimide and hydrogen atoms have been deleted for the sake of simplicity. TBs and XBs are depicted as black dotted lines and green dotted lines, respectively. Color code: gray carbon, red oxygen, purple iodine, brown bromine, dark teal tin

and in both of them the conformation is locked in by two

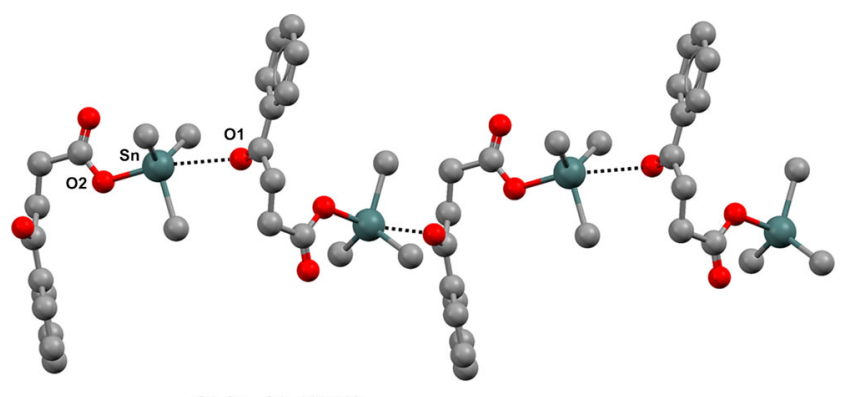

$02-S n \cdots 01: 168.38^{\circ}$

Fig. 7 Ball and stick representation (Mercury 3.9) of the 1D network in which the ketone oxygen of $O$-tricyclohexyltin-4-oxo-4-phenylbutanoate (APAZIB) functions as the TB acceptor site. Hydrogen atoms and five of the cyclohexyl carbons have been deleted for the sake of simplicity. Color code: gray carbon, red oxygen, dark teal tin

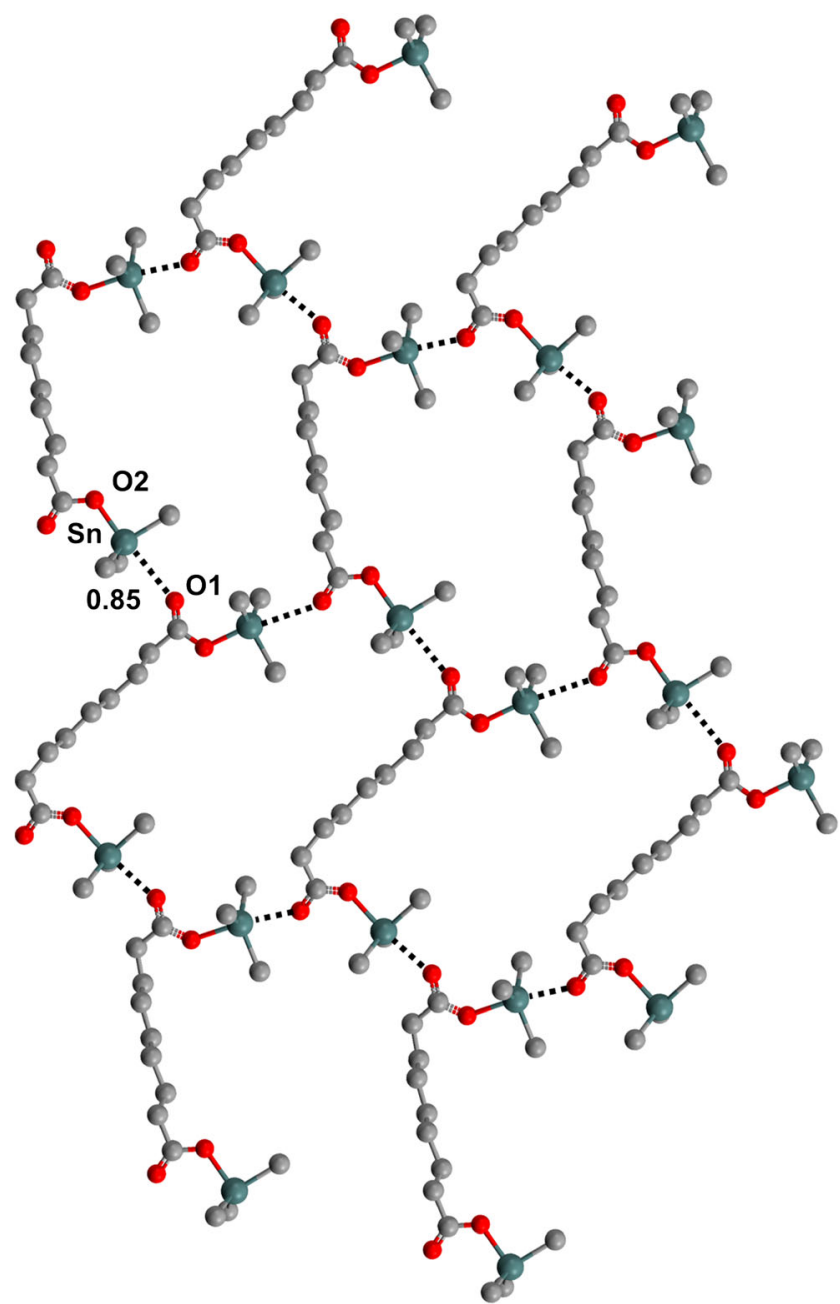

O2-Sn $\cdots 01: 172.33^{\circ}$

Fig. 8 Ball and stick representation (Mercury 3.9) of the two-dimensional network formed by bis(tricyclohexyltin)nonanoate (CUXSOF). Five atoms of the cyclohexyl residues bound to tin have been deleted for the sake of simplicity. Color code: gray carbon, red oxygen, dark teal tin

intramolecular TBs: an I-Sn $\cdots \mathrm{O}$ and a $\mathrm{C}-\mathrm{Sn} \cdots \mathrm{O}$ TB. The distances of the former interactions are shorter and those interactions are more directional than the latter ones (the $\mathrm{Nc}$ values are 0.70 and 0.72 for $\mathrm{I}-\mathrm{Sn} \cdots \mathrm{O}$ and 0.79 and 0.81 for $\mathrm{C}-\mathrm{Sn} \cdots \mathrm{O}$; the mean $\mathrm{I}-\mathrm{Sn} \cdots \mathrm{O}$ angle is $166.19^{\circ}$ and the mean $\mathrm{C}-\mathrm{Sn} \cdots \mathrm{O}$ angle is $166.68^{\circ}$ ).

Carbonyl oxygen atoms can act as effective TB acceptors. In (Z)-2-methyl-4-phenyl-3-(trimethylgermanyl)but-2-enoic acid (refcode QIBDOV) [52], a short $\mathrm{C}-\mathrm{Ge} \cdots \mathrm{O}$ contact is present in both conformations adopted by the compound in the crystals (Fig. 4, left) $(\mathrm{Nc}$ for $\mathrm{Ge} \cdots \mathrm{O}$ is 0.80 ; the $\mathrm{C}-\mathrm{Ge} \cdots \mathrm{O}$ angles are $174.17^{\circ}$ and $175.00^{\circ}$ ), and a shorter TB occurs in a trimethylstannylcarbomethoxy derivative (refcode KASYOS) [53], where a similar tin-based tecton is present ( $\mathrm{Nc}$ for $\mathrm{C}-$ $\mathrm{Sn} \cdots \mathrm{O}$ is 0.76 ) (Fig. 4, middle). Similar TBs are given by the carbonyl oxygens of carbamates (e.g., $N$-t-butyloxycarbonyl2-methyl-6-trimethylstannyl-4-phenyl-piperidine, refcode 


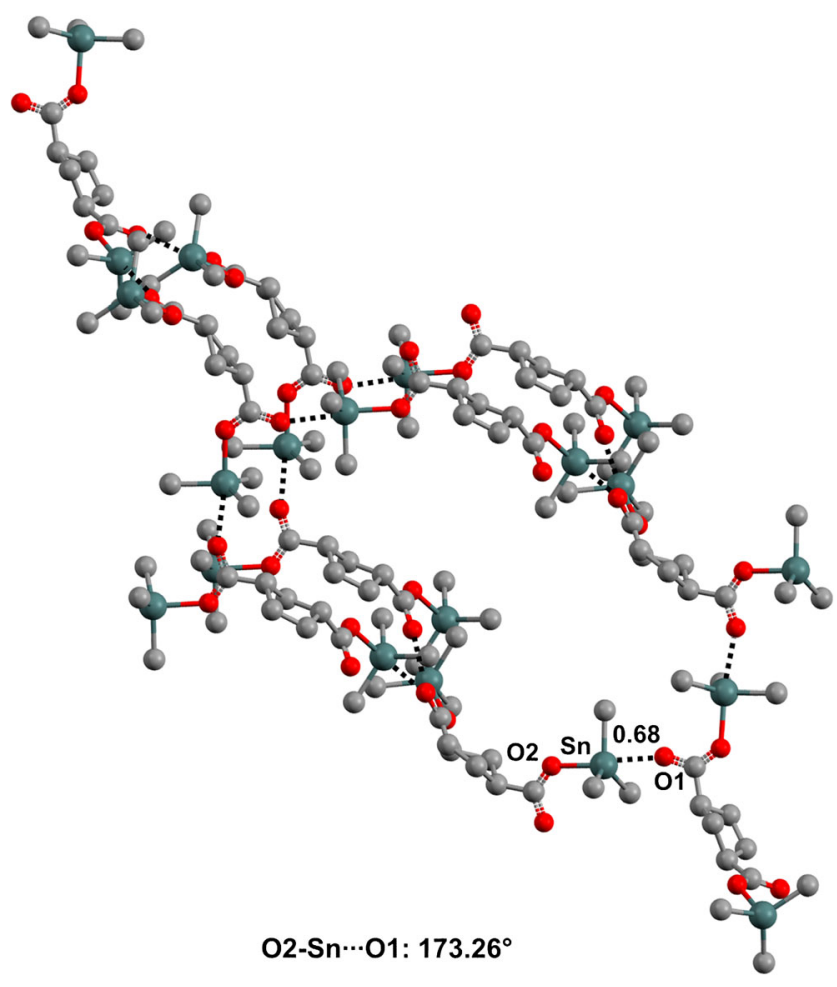

Fig. 9 Ball and stick representation (Mercury 3.9) of the threedimensional network with adamantanoid topology formed by bis(tri- $n$ butyltin)-1,2,2-trimethylcyclopentane-1,3-dicarboxylate (DIYFIB). Three atoms of the butyl residues bound to tin and the methyl pendants on the cyclopentyl rings have been deleted for the sake of simplicity. Color code: gray carbon, red oxygen, dark teal tin

EABFES; $\mathrm{Nc}=0.75$ and the $\mathrm{C}-\mathrm{Sn} \cdots \mathrm{O}$ angle is $165.31^{\circ}$; Fig. 4 , right) $[54,55]$ and several other carbonyl derivatives, e.g., amides [56], aldehydes [57, 58], and ketones [59].

The CSD contains both intra- and intermolecular TBs that have a carbonyl oxygen acting as the TB acceptor and facilitate the generation of discrete adducts [60] or infinite chains (one-dimensional networks, 1D nets). In ethyl trimethyltin diazoacetate (refcode SIWRAR) [61], the diazoacetate residue is expected to form a $\sigma$-hole on tin that is more positive than the $\sigma$ holes formed by the methyl groups. Consistent with this expectation, a tetrel-bonded infinite chain is present in the crystal of the compound (Fig. 5, top), wherein the carbonyl oxygen approaches the tin atom along the extension of the $\mathrm{N}_{2} \mathrm{C}-\mathrm{Sn}$ covalent bond (the $\mathrm{Sn} \cdots \mathrm{O}$ separation is $312.5 \mathrm{pm}$, which corresponds to an $\mathrm{Nc}$ value of 0.85 ; the $\mathrm{C}-\mathrm{Sn} \cdots \mathrm{O}$ angle is $176.46^{\circ}$ ). Similarly, the most positive $\sigma$-hole on germanium in 2,5-bis(trimethylgermyl)thiophene-1,1-dioxide (refcode QAHXIG) [62] is expected to occur opposite to the $\mathrm{O}_{2} \mathrm{SC}-\mathrm{Ge}$ covalent bond, and an infinite chain (Fig. 5, bottom) is formed in which the sulfonyl oxygens approach germanium atoms along the extension of each $\mathrm{O}_{2} \mathrm{SC}-\mathrm{Ge}$ covalent bond, leading to a particularly linear geometry (the $\mathrm{Ge} \cdots \mathrm{O}$ separation corresponds to an $\mathrm{Nc}$ value of 0.97 , and the $\mathrm{C}-\mathrm{Ge} \cdots \mathrm{O}$ angle is $179.77^{\circ}$ ).

$N$-triethylstannylsuccinimide (refcode FUSZIC) [63] is a self-complementary module that forms tetrel-bonded infinite
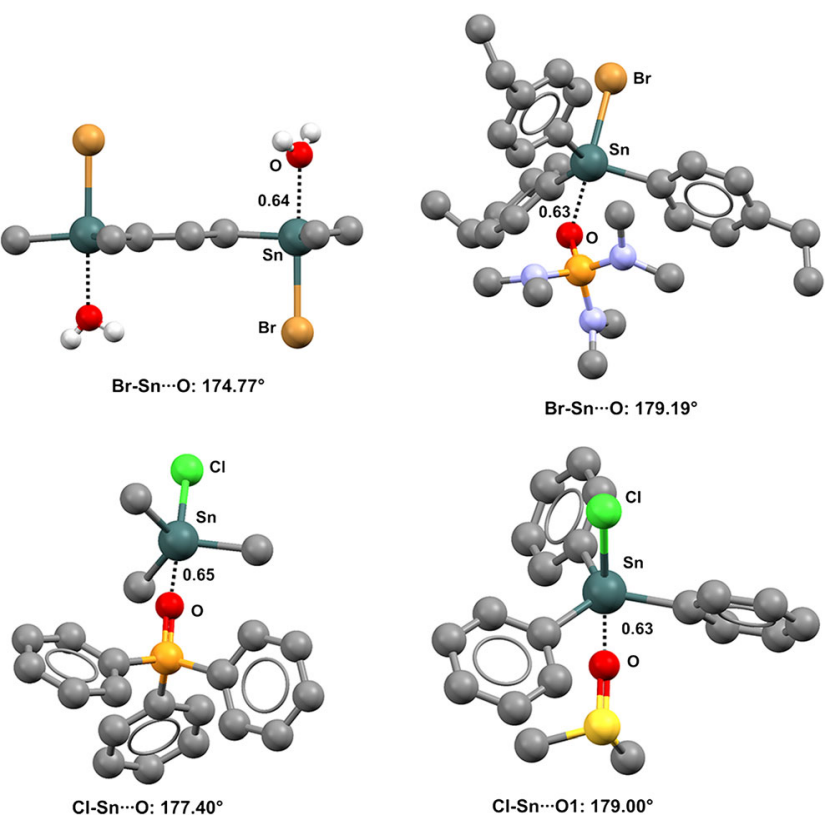

Fig. 10 Ball and stick representations (Mercury 3.9) of the trimer formed by 1,3-bis(bromodimethylstannyl)propane and water (XINROB, top left), of the dimer formed by bromo-tris( $p$-ethylphenyl)tin and hexamethylphosphoramide (HEVQIJ, top right), of the dimer formed by chlorotrimethyltin and triphenylphosphine oxide (HIGRUK01, bottom left), and of the dimer formed by chlorotriphenyltin and dimethyl sulfoxide (RUGYOI, bottom right). Hydrogen atoms and the 2,2'-bipyridine in XINROB have been deleted for the sake of simplicity. TBs are depicted as black dotted lines. Color code: gray carbon, red oxygen, blue nitrogen, orange phosphorus, green chlorine, brown bromine, yellow sulfur, dark teal tin

chains (one-dimensional networks, 1D nets) (Fig. 6, top). Consistent with the expected involvement of an $s p^{2}$ lone pair of the carbonyl oxygen as the nucleophilic site that interacts with $\mathrm{Sn}$ along the extension of the $\mathrm{N}-\mathrm{Sn}$ covalent bond, the $\mathrm{Sn} \cdots \mathrm{O}=\mathrm{C}$ angle is $138.28^{\circ}$ and the tin atom is approximately in the plane of the succinimide (the distance between the mean square plane through the seven heavy atoms of the succinimide moiety and the tetrel-bonded tin atom is $219 \mathrm{pm}$ ). The halogen-bonded infinite chains formed by $\mathrm{N}$ chloro- and $\mathrm{N}$-bromosuccinimide (refcodes CSUCIM01 and NBSUCA, respectively) [64] are also reported in Fig. 6 (middle and bottom) in order to highlight the analogous supramolecular features of TB and XB.

In several structures in the CSD, the tin atom of a trialkylalkanoyltin moiety found in $\mathrm{R}_{3} \mathrm{Sn}-\mathrm{OC}(\mathrm{O}) \mathrm{R}^{\prime}$ derivatives shows the presence of a TB with a carbonyl oxygen located opposite to the covalent $\mathrm{Sn}-\mathrm{O}$ bond, and onedimensional [65], two-dimensional [66], or threedimensional [67] networks are formed depending on the overall structure of the compound (Figs. 7, 8, and 9).

Various other oxygen functionalities can act as donors of electron density to organotin and germanium derivatives, e.g., water [68-70], sulfoxides and sulfones [71-74], as well as 

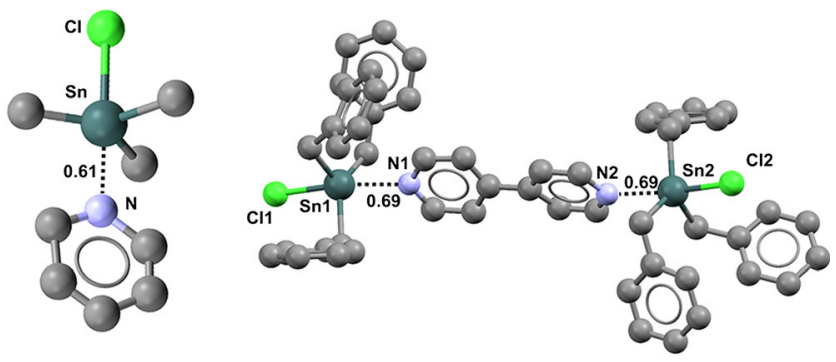

$\mathrm{Cl}-\mathrm{Sn} \cdots \mathrm{N}: 179.18^{\circ}$

Cl1-Sn1 $\cdots \mathrm{N} 1: 169.62^{\circ}$

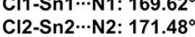

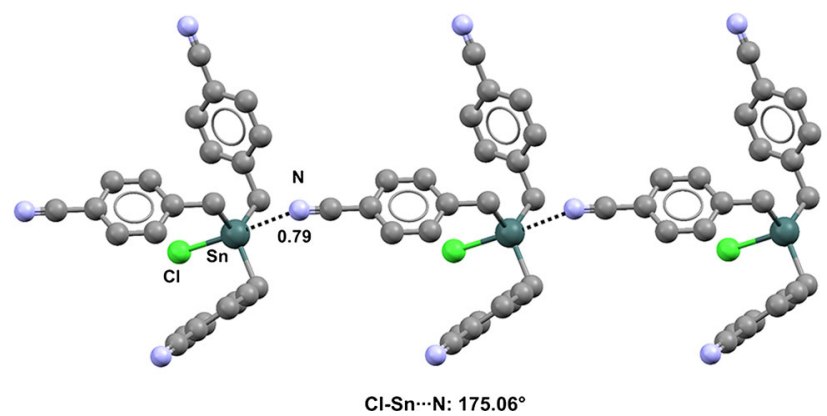

Fig. 11 Ball and stick representations (Mercury 3.9) of the dimer formed by chloro(trimethyl)tin and pyridine (CMEPSN, top left), of the trimer formed by chloro(tribenzyl)tin and 4,4'-bipyridyl (FEJFUW, top right), and of the 1D chain formed by chlorotris(4-cyanobenzyl)tin (BIBQIN, bottom). Hydrogen atoms have been deleted for the sake of simplicity. TBs are depicted as black dotted lines. Color code: gray carbon, blue nitrogen, green chlorine, dark teal tin

phosphine oxides, hexamethylphosphortriamide, and their analogs [75-81] (Fig. 10).

\section{Nitrogen atoms as TB acceptors}

The CSD contains several structures in which the nitrogen atom of amine, pyridine, and cyano moieties forms a close contact with a tin or germanium atom (Fig. 11), thus showing that - similar to oxygen atoms — nitrogen atoms can act as TB acceptors, and this can be the case whether there is $s p^{3}, s p^{2}$, or $s p$ hybridization.

The ability of nitrogen atoms of tertiary amines to form close contacts with organogermanium and -tin derivatives is particularly well documented. For instance, two symmetrically nonequivalent molecules are present in crystals of tris(2-((dimethylamino)methyl)phenyl)germane (refcode GAGYIW) [82], and the conformations of both molecules are influenced by three intramolecular $\mathrm{C}-\mathrm{Ge} \cdots \mathrm{N}$ TBs (Fig. 12, left) (the Nc values of these TBs span the range $0.82-0.84$, and the $\mathrm{C}-\mathrm{Ge} \cdots \mathrm{N}$ angles vary between $172.45^{\circ}$ and $176.79^{\circ}$ ). The $\mathrm{C}-\mathrm{N}-\mathrm{C}$ angles vary between $109.70^{\circ}$ and $113.25^{\circ}$, indicating that nitrogen atoms of the tertiary amine moieties adopt a tetrahedral conformation and the lone pairs align with the extensions of the covalent $\mathrm{C}-\mathrm{Ge}$ bonds, as expected for $\sigma$-hole interactions (the $\mathrm{C}-\mathrm{N} \cdots \mathrm{Ge}$ angles span the range $82.34-120.39^{\circ}$ ).

Imine nitrogen atoms behave in a similar manner to amine nitrogens. A close linear $\mathrm{C}-\mathrm{Ge} \cdots \mathrm{N}$ interaction affects the conformation adopted by 1-(trimethylsilylimino(diphenyl)phosphoranyl)2-(triphenylgermyl)benzene ( $\mathrm{Nc}$ for $\mathrm{Ge} \cdots \mathrm{N}$ is 0.85 ; the $\mathrm{C}-\mathrm{Ge} \cdots \mathrm{N}$ angle is $173.79^{\circ}$ ) (refcode VIQXIC) [83] (Fig. 12, right). In the crystal of this compound, the $\mathrm{P}=\mathrm{N} \cdots \mathrm{Ge}$ angle is $96.80^{\circ}$, and the germanium atom is approximately in the iminophosphoranyl plane (the distance between the tetrel-bonded germanium atom and the mean square plane through the phosphorus, nitrogen, and silicon atoms is $263 \mathrm{pm}$ ), suggesting that the lone pair at nitrogen aligns with the extension of the covalent $\mathrm{C}-\mathrm{Ge}$ bond.

Close intramolecular $\mathrm{Ge} \cdot \cdots \mathrm{N}$ contacts affect the conformation of a family of 4,6,11-trioxa-1-aza-5-germabicyclo[3.3.3]undecanes (germatrane derivatives). In the solid, 5-( $t$-butyl)-germatrane (refcode BUWBUQ) [84] adopts an endo conformation (Fig. 13, left) where the $\mathrm{C}-\mathrm{Ge} \cdots \mathrm{N}$ separation is as short as $223.6 \mathrm{pm}(\mathrm{Nc}=$ 0.61). 5-Bromogermatrane (refcode BUWCUR) [85] behaves similarly (Fig. 13, middle), and the $\mathrm{Br}-\mathrm{Ge} \cdots \mathrm{N}$ separation is even shorter

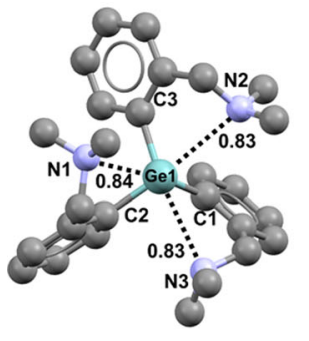

C1-Ge1N1: $173.89^{\circ}$

C2-Ge1N.N2: $173.90^{\circ}$

C3-Ge1N.N3: $172.66^{\circ}$

C4-Ge2..N4: $174.37^{\circ}$

C5-Ge2 $\cdots$ N5: $176.79^{\circ}$

C6-Ge2 $\cdots$ N6: $172.45^{\circ}$

Fig. 12 Ball and stick representations (Mercury 3.9) of tris(2((dimethylamino)methyl)phenyl)germane (GAGYIW, left) and 1( trime thylsilylimino (diphenyl)phosphoranyl)-2(triphenylgermyl)benzene (VIQXIC, right) derivatives. TBs are depicted as black dotted lines; hydrogen atoms have been omitted for clarity. $\mathrm{Nc}$ values are shown close to the respective interactions. Color code: gray carbon, light blue nitrogen, yellow sulfur, pearl white silicon, orange phosphorus, light teal germanium 


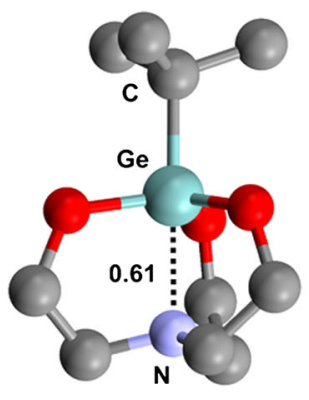

C-Ge $\cdots N$ : $180.00^{\circ}$

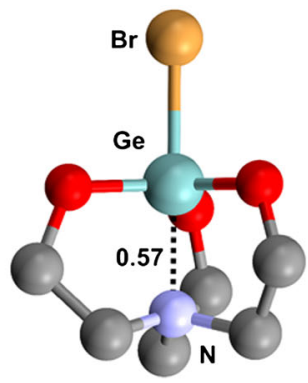

$\mathrm{Br}-\mathrm{Ge} \cdots \mathrm{N}: \mathbf{1 7 9}^{\circ} .73^{\circ}$

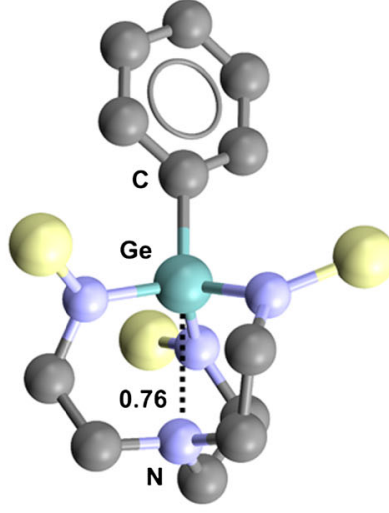

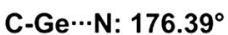

Fig. 13 Ball and stick representations (Mercury 3.9) of 5-( $t_{-}$ butyl)germatrane (BUWBUQ, left), 5-bromogermatrane (BUWCUR, middle), and phenyl(tris(2-(trimethylsilylamido)ethyl)amine$\left.N, N^{\prime}, N^{\prime \prime}\right)$ germanium (XUSLOM, right). TBs are depicted as black dotted lines; hydrogen atoms and methyl substituents on the silyl moieties of XUSLOM have been omitted for clarity. Nc values are shown close to the respective interactions. Color code: gray carbon, red oxygen, light blue nitrogen, bronze bromine, pearl white silicon, light teal germanium
(208.4 pm, Nc=0.57) than in BUWBUQ, consistent with the fact that bromine is more electronegative than carbon and the $\sigma$-hole opposite the $\mathrm{Br}-\mathrm{Ge}$ covalent bond is probably more positive than that opposite the $\mathrm{C}-\mathrm{Ge}$ bond. Analogous endo conformations and Ge $\cdots \mathrm{N}$ distances that are much shorter than the sum of the van der Waals radii of the germanium and nitrogen atoms are observed in other germatrane derivatives [86-88] and related systems [89, 90] (Fig. 13, right). Similar behavior is encountered in the crystals of tin analogs. 5-Methyl-1-aza-5-stannabicyclo[3.3.3] undecane (refcode FEWXOU) [79] and its 5-fluoro [91], 5-chloro [92], 5-bromo [91], and 5-iodo [91] analogs (refcodes ZANKEE, DAYMUL, ZANKOO, ZANKUU, respectively) all show close $\mathrm{Sn} \cdots \mathrm{N}$ contacts (Fig. 14).

As in organogermanium derivatives, the nitrogen atom of the 2-(dimethylaminomethyl)phenylstannyl moiety forms an intramolecular TB which affects the conformation of the respective compound in the solid. This is the case for (cyclopenta-2,4-dien-1yl)-(2-(dimethylaminomethyl)phenyl)diphenyl tin (refcode

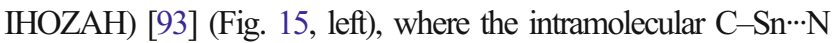
distance corresponds to an $\mathrm{Nc}$ value of 0.74 and the $\mathrm{C}-\mathrm{Sn} \cdots \mathrm{N}$ angle is $171.08^{\circ}$, congruent with an attractive interaction between the lone pair of the tertiary amine nitrogen and the $\sigma$-hole along the extension of the C-Sn covalent bond. Analogous $\mathrm{Sn} \cdots \mathrm{N}$ interactions are present in structurally related derivatives [94-96]. A five-membered and tetrel-bonded ring similar to that of IHOZAH is afforded by (3aminopropyl)triphenyltin (refcode COKVUV) [97] (Fig. 15, right), which shows an $\mathrm{Sn} \cdots \mathrm{N}$ interaction where $\mathrm{Nc}$ is 0.74 and the $\mathrm{C}-\mathrm{Sn} \cdots$ $\mathrm{N}$ angle is $175.81^{\circ}$.

The tin atom of $\mathrm{R}_{3} \mathrm{Sn}-\mathrm{OC}(\mathrm{O}) \mathrm{R}^{\prime}$ derivatives is a good TB donor and frequently interacts with the oxygen atom of a carbonyl group (Figs. 7-9) or the nitrogen atom of a pyridine moiety. The intermolecular $\mathrm{Sn} \cdot \cdots \mathrm{N}$ interaction occurs opposite to the covalent $\mathrm{Sn}-\mathrm{O}$ bond, and discrete trimers [98] (Fig. 16, top) or one-dimensional [99-102] (Fig. 16, bottom) or twodimensional [103] networks (Fig. 17) are formed depending on the ability of the tin derivative to function as a mono-, bi-, or polydentate tecton.

The nitrogen atom of pyridine derivatives forms close contacts with tin along the extensions of not only $\mathrm{O}-\mathrm{Sn}$ bonds but also C-Sn, Cl-Sn, Br-Sn, I-Sn, and S-Sn bonds [99, 101, $104,105]$. In all cases, the geometric features of the adducts indicate that the nitrogen lone pair is oriented along the

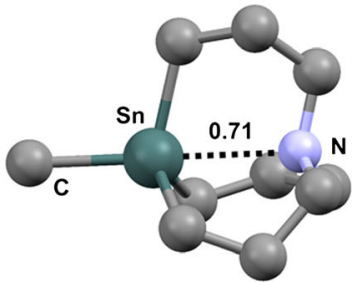

F-Sn $\cdots \mathrm{N}: 179.57^{\circ}$

Fig. 14 Ball and stick representations (Mercury 3.9) of 5-methyl-1-aza-5stannabicyclo(3.3.3) undecane (FEWXOU, left) and 5-fluoro-1-aza-5stannatricyclo(3.3.3)undecane (ZANKEE, right). TBs are depicted as

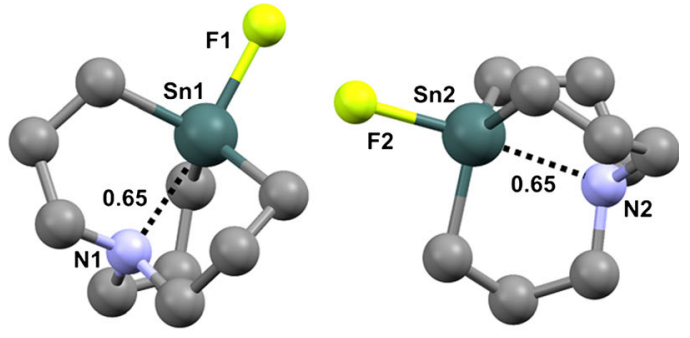

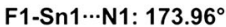

F2-Sn2 $\cdots$ N2: $172.73^{\circ}$

black dotted lines; hydrogen atoms have been omitted for clarity. $\mathrm{Nc}$ values are shown close to the respective interactions. Color code: gray carbon, light blue nitrogen, yellowish green fluorine, dark teal tin 

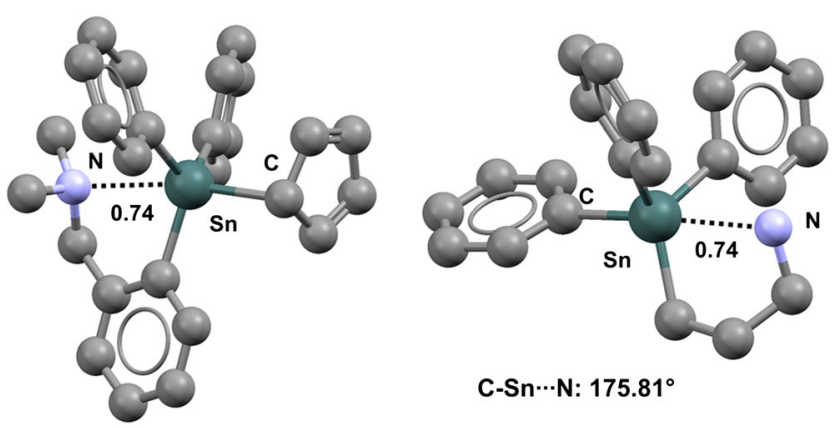

C-Sn $\cdots N$ : $175.81^{\circ}$

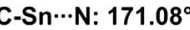

Fig. 15 Ball and stick representations (Mercury 3.9) of (cyclopenta-2,4dien-1-yl)-(2-(dimethylaminomethyl)phenyl)diphenyltin (left) and (3aminopropyl)triphenyltin (IHOZAH, right). TBs are depicted as black dotted lines; hydrogen atoms have been omitted for clarity. Nc values are shown close to the respective interactions. Color code: gray carbon, light blue nitrogen, dark teal tin

extension of one of the covalent bonds of tin. For instance, in the infinite chain formed by the dithiocarbamate reported in Fig. 18 (refcode UGEFIX), the $\mathrm{S}-\mathrm{Sn} \cdots \mathrm{N}$ angle is $174.50^{\circ}$, the geometry around the nitrogen is strictly trigonal planar, and tin is nearly in the pyridine plane (the two $\mathrm{C}\left(s p^{2}\right) \mathrm{N} \cdots \mathrm{Sn}$ angles are $121.18^{\circ}$ and $122.40^{\circ}$, and the distance of tin from the mean square plane through the pyridine ring is $85 \mathrm{pm}$ ).

The cyano group seems to be able to act as an effective TB acceptor group via the lone pair at the nitrogen. Moreover, due to its strong electron-withdrawing ability, it is expected that when the cyano group is directly bound to a tin or germanium atom, the $\sigma$-hole opposite the covalent $\mathrm{NC}-\mathrm{Sn} / \mathrm{Ge}$ bond will be particularly positive. Indeed, trimethyltin cyanide (refcode TIMSNC01) and dimethyltin dicyanide (refcode DMCYSN)

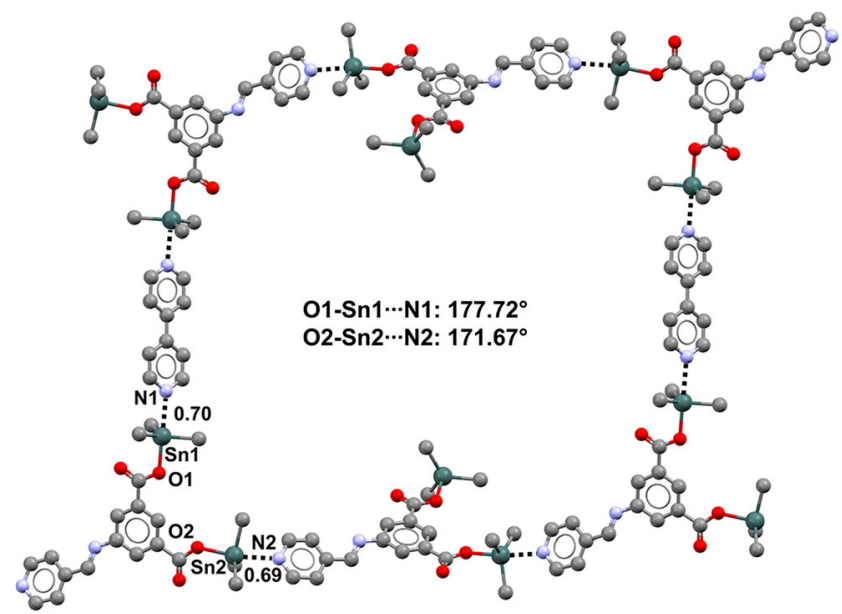

Fig. 17 Ball and stick representation (Mercury 3.9) of the network generated by di(tri-n-butyl)stannyl-5-( (pyridin-4ylmethylene)amino)isophthalate with 4,4'-bipyridine (TISVEY). TBs are depicted as black dotted lines; three atoms of the butyl residues at tin and hydrogen atoms have been deleted for the sake of simplicity. Nc values are shown close to the respective interactions. Color code: gray carbon, red oxygen, light blue nitrogen, dark teal tin

are both self-complementary modules that form infinite chains [106] and square 2D networks [107], respectively (Fig. 19), by pairing TB donor and TB acceptor sites. Dimethylgermanium dicyanide (refcode DMCYGE) shows somewhat similar behavior.

Tetrakis(2-cyanobenzyl)tin (refcode JIWROX) [108] (Fig. 20) functions as a self-complementary tecton, as the cyano group of one molecule aligns with the extension of one of the $\mathrm{C}-\mathrm{Sn}$ covalent bonds of an adjacent molecule,
Fig. 16 Ball and stick representations (Mercury 3.9) of the trimer formed by (ferrocene1-carboxylato)triphenyltin and 4,4'-bipyridine (IVUVUR, top) and of the infinite chain formed by (pyridine-4-

carboxylato)tricyclohexyltin (UZAVUN, bottom). TBs are depicted as black dotted lines; hydrogen atoms have been deleted for the sake of simplicity. $\mathrm{Nc}$ values are shown close to the respective interactions. Color code: gray carbon, red oxygen, orange iron, light blue nitrogen, dark teal tin
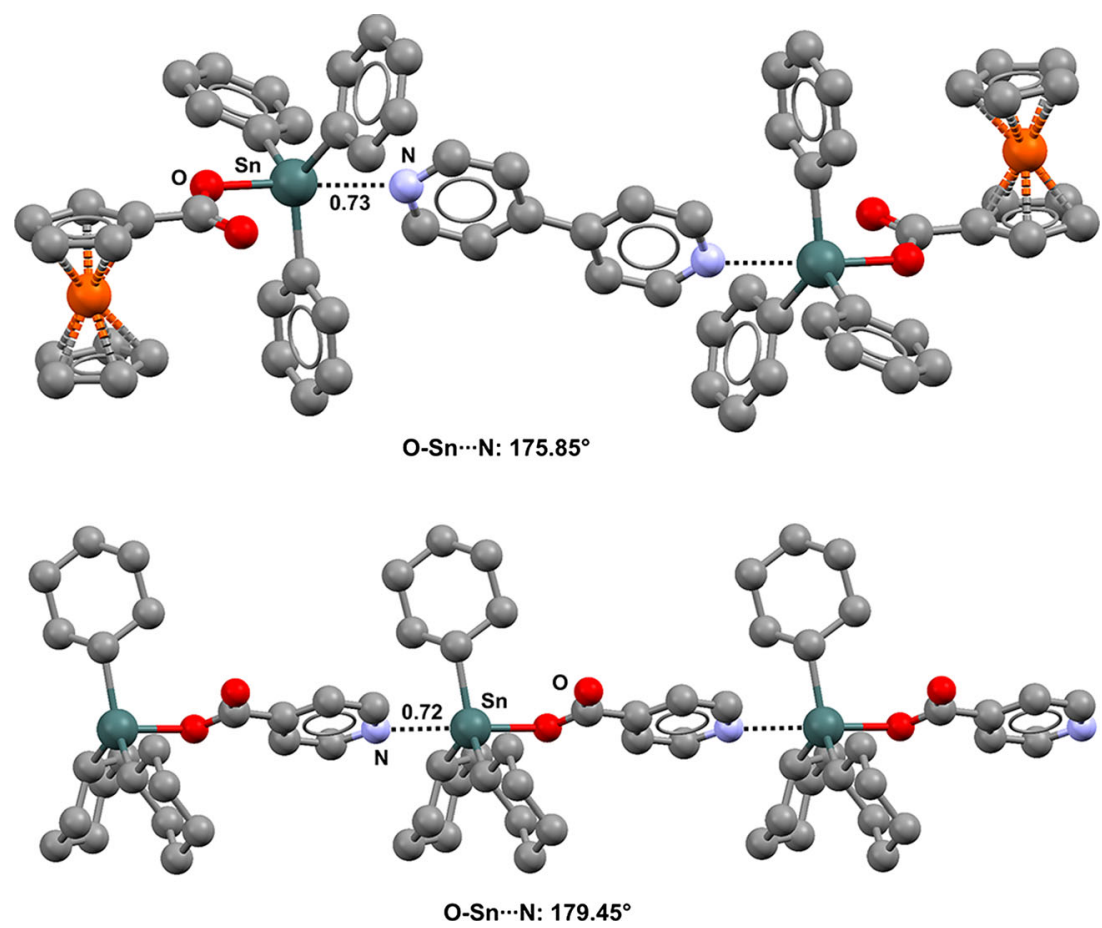


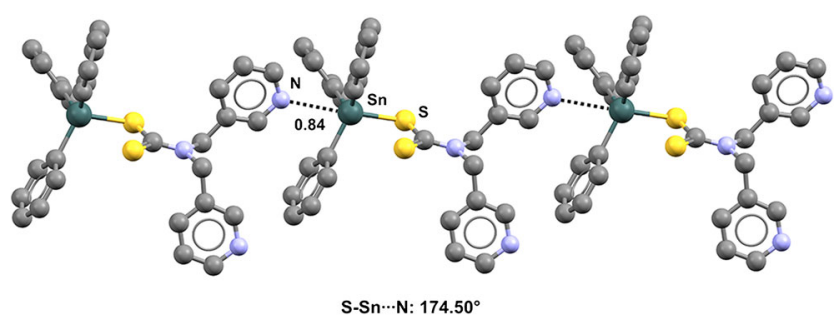

Fig. 18 Ball and stick representation (Mercury 3.9) of the onedimensional network formed by (bis(pyridin-3-ylmethyl) carbamodithioato)triphenyltin (UGEFIX). TBs are depicted as black dotted lines; hydrogen atoms have been deleted for the sake of simplicity. Nc values are shown close to the respective interactions. Color code: gray carbon, yellow sulfur, light blue nitrogen, dark teal tin

ultimately forming infinitely long tetrel-bonded ribbons $\left(\mathrm{Nc}=0.96\right.$; the $\mathrm{C}-\mathrm{Sn} \cdots \mathrm{N}$ angle is $\left.178.46^{\circ}\right)$.

In 2-(dimethylaminomethyl)phenyl)cyanodiphenyltin and bis(2-(dimethylaminomethyl)phenyl)dicyanotin (refcodes WUVKOP and WUVLOQ, respectively) [109], one and two $\mathrm{NC}-\mathrm{Sn} \cdots \mathrm{N}$ close contacts are present, respectively, and the amine nitrogen acts as the TB acceptor site in all cases (Fig. 21). This may suggest that a $\mathrm{N}\left(s p^{3}\right)$ atom is a better TB acceptor than a $\mathrm{N}(s p)$ atom. The same ability to act as a donor of electron density is observed in $\mathrm{XB}$ formation.

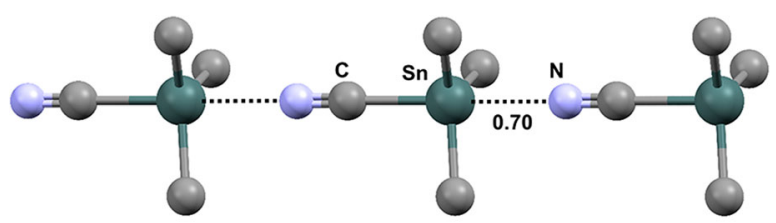

C-Sn $\cdots \mathrm{N}: 178.68^{\circ}$

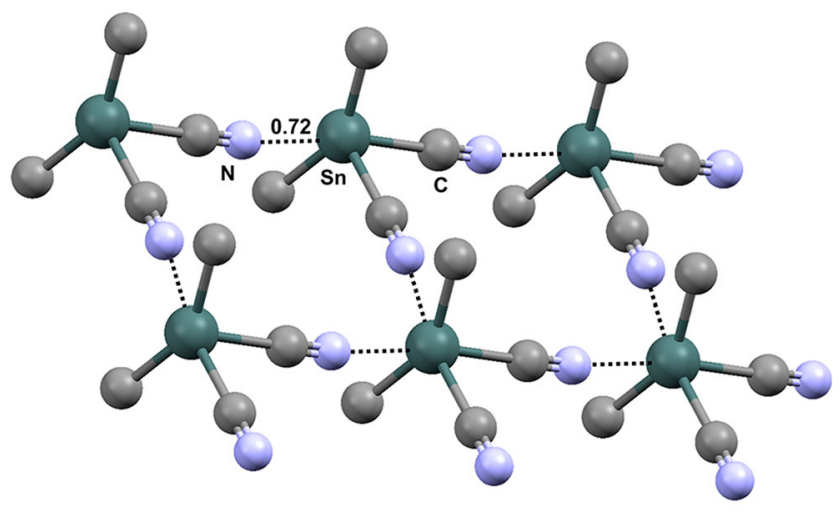

C-Sn-N: $167.88^{\circ}$

Fig. 19 Ball and stick representations (Mercury 3.9) of the 1D infinite chain formed by trimethyltin cyanide (TIMSNC01, top) and the 2D network generated by dimethyltin dicyanide (DMCYSN, bottom). TBs are depicted as black dotted lines; hydrogen atoms have been deleted for the sake of simplicity. $\mathrm{Nc}$ values are shown close to the respective interactions. Color code: gray carbon, light blue nitrogen, dark teal tin

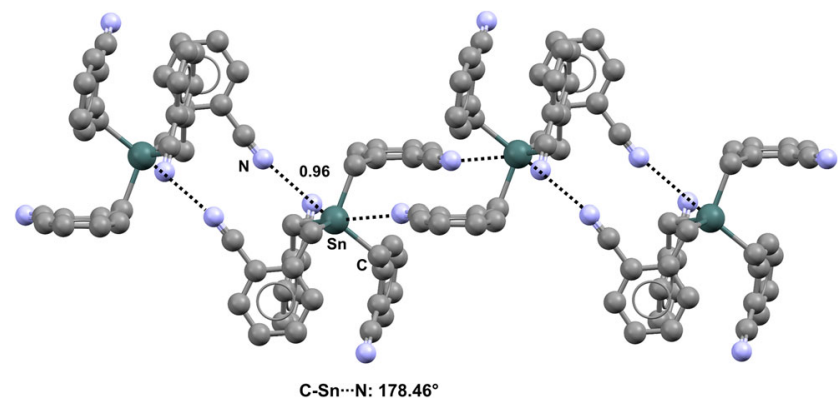

Fig. 20 Ball and stick representation (Mercury 3.9) of the network formed by tetrakis(2-cyanobenzyl)tin (JIWROX). TBs are depicted as black dotted lines; hydrogen atoms have been deleted for the sake of simplicity. Nc values are shown close to the respective interactions. Color code: gray carbon, light blue nitrogen, dark teal tin

\section{Halogen atoms as tetrel bond acceptors}

Structures in the CSD reveal that the four halogens $\mathrm{F}, \mathrm{Cl}, \mathrm{Br}$, and I can all form close contacts with tetravalent germanium and tin atoms in organic derivatives. These interactions can be rationalized as TBs due to the fact that the halogen atom is located approximately along the extension of one of the covalent bonds formed by the germanium or tin. The bond with the most electron-withdrawing group is preferentially involved in the formation of these close contacts.

For instance, crystals of bis(2,5-bis(trifluoromethyl) phenyl)(dichloro)germane (refcode ZAVCUW) have two symmetrically nonequivalent molecules in the unit cell [110]. Both of these molecules show two fairly short and linear TBs oriented along the extensions of the $\mathrm{Cl}-\mathrm{Ge}$ bonds (Nc values span the range $0.78-0.79$; the $\mathrm{C}-\mathrm{Ge} \cdots \mathrm{F}$ angles are between $176.15^{\circ}$ and $174.93^{\circ}$ ) (Fig. 22, left). Analogously, an
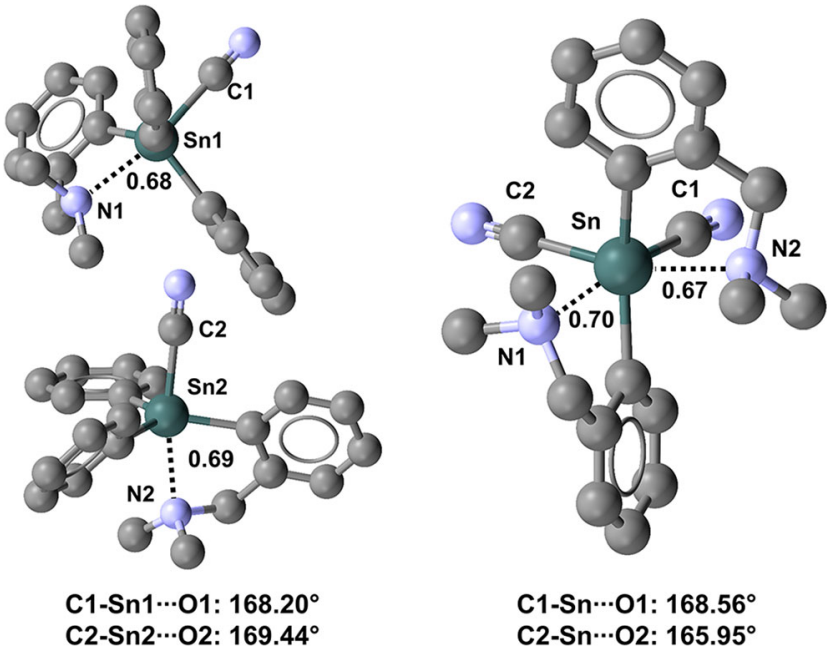

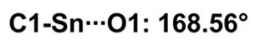

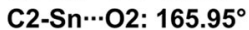

Fig. 21 Ball and stick representations (Mercury 3.9) of the conformations adopted by cyano-2-(dimethylaminomethyl)phenyl)diphenyltin (WUVKOP, left) and bis(2-(dimethylaminomethyl)phenyl)dicyanotin (WUVLOQ, right). TBs are depicted as black dotted lines; hydrogen atoms have been deleted for the sake of simplicity. Nc values are shown close to the respective interactions. Color code: gray carbon, light blue nitrogen, dark teal tin 

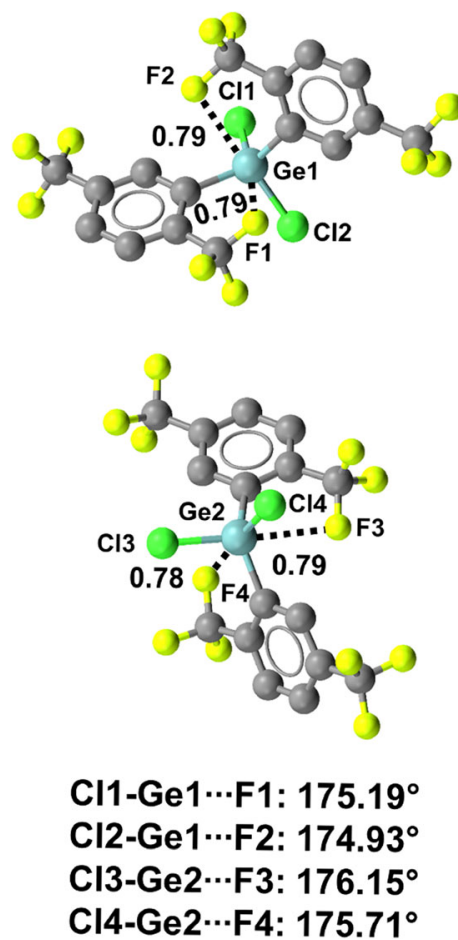

Fig. 22 Ball and stick representations (Mercury 3.9) of the conformations adopted by bis(2,5-bis(trifluoromethyl)phenyl)(dichloro)germane (ZAVCUW, left) and (1,2,3,3,3-pentafluoroprop-1-en-1-yl)triphenyltin (ADUKOB, right). TBs are depicted as black dotted lines; hydrogen atoms have been deleted for the sake of simplicity. Nc values are shown close to the respective interactions. Color code: gray carbon, yellowish green fluorine, light teal germanium, dark teal tin

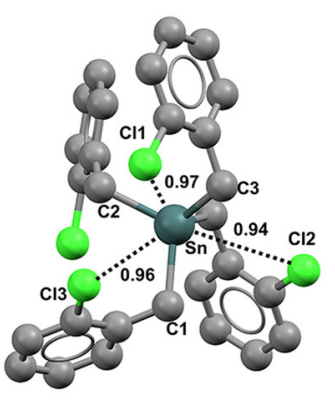

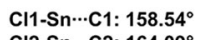
$\mathrm{Cl} 2-\mathrm{Sn} \cdots \mathrm{C} 2: 164.09^{\circ}$ Cl3-Sn $\cdots$ C3: $155.47^{\circ}$

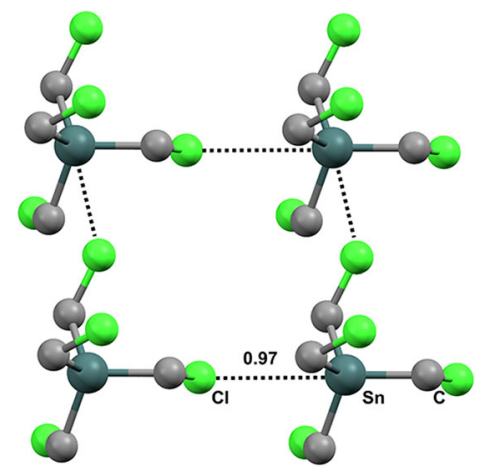

Cl-Sn $\cdots$ C: $175.71^{\circ}$
Fig. 24 Ball and stick representations (Mercury 3.9) of the conformation adopted by tetrakis(2-chlorobenzyl)tin (CEWGEQ01, left) and the network generated by tetrakis(chloromethyl)tin (UGATEB, right). TBs are depicted as black dotted lines; hydrogen atoms have been omitted for clarity. $\mathrm{Nc}$ values are shown close to the respective interactions. Color code: gray carbon, green chlorine, dark teal tin

intramolecular $\mathrm{C}-\mathrm{Ge} \cdots \mathrm{F}$ close contact locks in the conformation of (1,2,3,3,3-pentafluoroprop-1-en-1-yl)triphenyl germanium (refcode ADUKUH) [111] in the solid and allows for the formation of a tetrel-bonded five-membered ring (the $\mathrm{Nc}$ value of $\mathrm{Ge} \cdots \mathrm{F}$ is 0.86 ; the $\mathrm{C}-\mathrm{Ge} \cdots \mathrm{F}$ angle is $166.80^{\circ}$ ). The tin analog of ADUKUH (refcode ADUKOB) behaves similarly, as an intramolecular $\mathrm{C}-\mathrm{Sn} \cdots \mathrm{F}$ TB is present in both of the independent molecules present in the unit cell of the crystal, leading to a tetrel-bonded ring (Fig. 22, right).
Fig. 23 Ball and stick representations (Mercury 3.9) of $1 \mathrm{D}$ chains generated by fluorotricyclohexyltin (BAJWOY, top),

dichlorodimethyltin (DMSNCL, middle), and dibromodiethyltin (DESNBR, bottom). TBs are depicted as black dotted lines hydrogen atoms have been omitted for clarity. Nc values are shown close to the respective interactions. Color code: gray carbon, brown bromine, green chlorine, yellowish green fluorine, dark teal tin

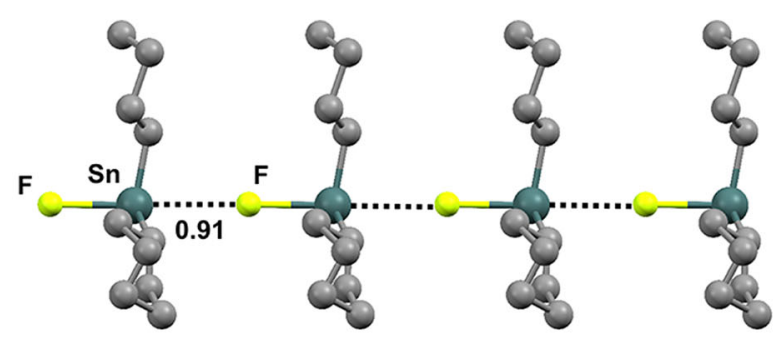

F-Sn $\cdots F: 178.85^{\circ}$

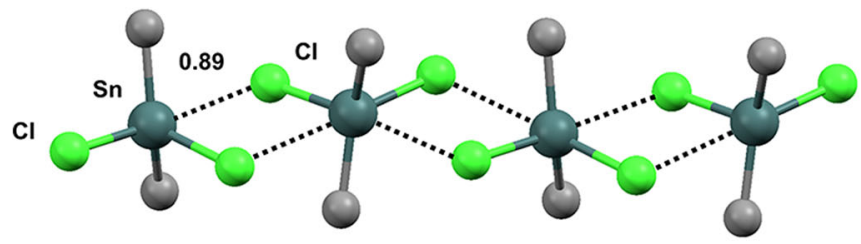

$\mathrm{Cl}-\mathrm{Sn} \cdots \mathrm{Cl}: 178.59^{\circ}$

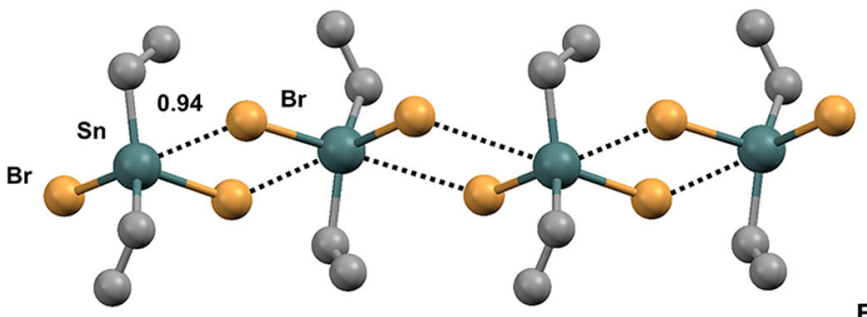

$\mathrm{Br}-\mathrm{Sn} \cdots \mathrm{Br}: 179.55^{\circ}$ 
Interestingly, tricyclohexyltin fluoride (refcode BAJWOY) [112] is a self-complementary module, as the fluorine atom of one molecule forms a short and remarkably linear TB along the extension of the covalent F-Sn bond of an adjacent molecule, and infinitely long chains are generated (Fig. 23, top) (the Nc value for $\mathrm{Sn} \cdots \mathrm{F}$ is 0.91 ; the $\mathrm{F}-\mathrm{Sn} \cdots \mathrm{F}$ angle is $178.85^{\circ}$ ). Similar behavior is shown by several other organotin derivatives bearing one, two, or three halogen atoms at the heavy tetrel [113-116] (Fig. 23).

Crystals of tetrakis(2-chlorobenzyl)tin (refcode CEWGEQ) [117] provide a nice example of intramolecular $\mathrm{C}-\mathrm{Sn} \cdots \mathrm{Cl}$ interactions, as three such contacts $(\mathrm{Nc}$ values range from 0.94 to 0.97 ) lock in the molecular conformation (Fig. 24, left). Interestingly, tetrakis(2-methoxybenzyl)tin (refcode HEVFOD) [118] and tetrakis(2-fluorobenzyl)tin (refcode VULSOM) [119] present four intramolecular C-

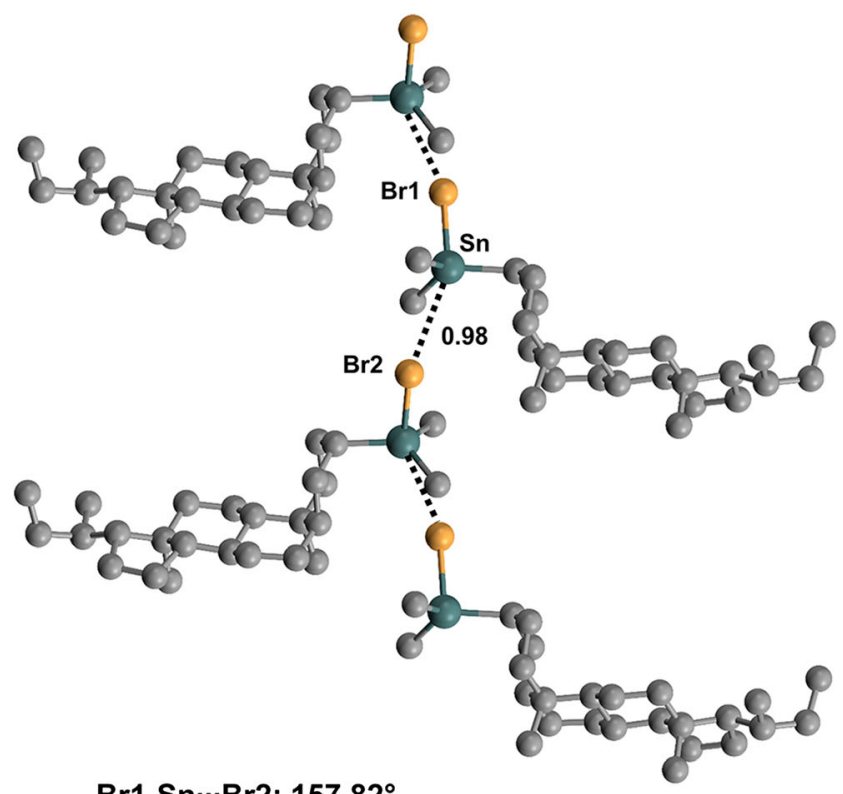

$\mathrm{Br} 1-\mathrm{Sn} \cdots \mathrm{Br} 2: 157.82^{\circ}$

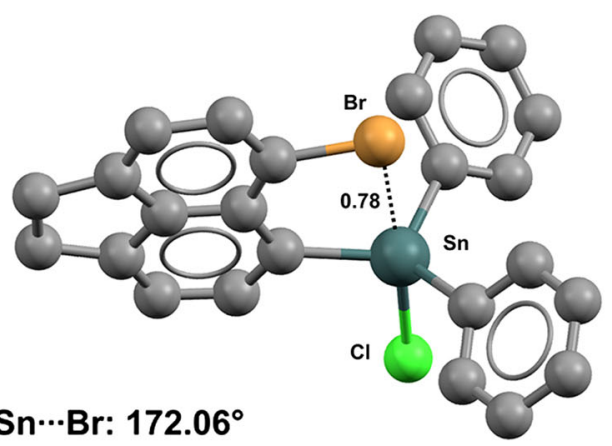

Fig. 25 Ball and stick representations (Mercury 3.9) of the conformation adopted by chloro(6-bromo-1,2-dihydroacenaphthylen-5-yl)diphenyltin (VEKKUT, bottom) and the $1 \mathrm{D}$ chain generated by $3 \beta$ (bromodimethylstannyl)-24-nor-5 $\beta$-cholane (MISYAO, top). TBs are depicted as black dotted lines; hydrogen atoms have been omitted for clarity. Nc values are shown close to the respective interactions. Color code: gray carbon, brown bromine, dark teal tin
$\mathrm{Sn} \cdots \mathrm{O}$ and $\mathrm{C}-\mathrm{Sn} \cdots \mathrm{F}$ TBs in their respective crystals. Tetrakis(chloromethyl)tin (refcode UGATEB) [120] also provides a good example of intermolecular $\mathrm{C}-\mathrm{Sn} \cdots \mathrm{Cl}$ contacts. The molecule is a self-complementary bidentate TB donor (at tin) and acceptor (at chlorine) (Fig. 24, right), and a tetrelbonded $(4,4)$ network is formed wherein UGATEB sits at the nodes.

The conformation of diphenyl(6-bromo-1,2dihydroacenaphthylen-5-yl)chlorotin (refcode VEKKUT) [121] is influenced by an intramolecular TB where the bromine atom is localized along the extension of the $\mathrm{Cl}-\mathrm{Sn}$ bond $\left(\mathrm{Nc}=0.78\right.$; the $\mathrm{Cl}-\mathrm{Sn} \cdots \mathrm{Br}$ angle is $\left.172.06^{\circ}\right)$ (Fig. 25, bottom) [121]. Similar $\mathrm{Cl}-\mathrm{Sn} \cdots \mathrm{Br}$ contacts are present in various other (6-bromo-1,2-dihydroacenaphthylen-5-yl)tin derivatives. Bromine atoms can also be involved in intermolecular TBs.

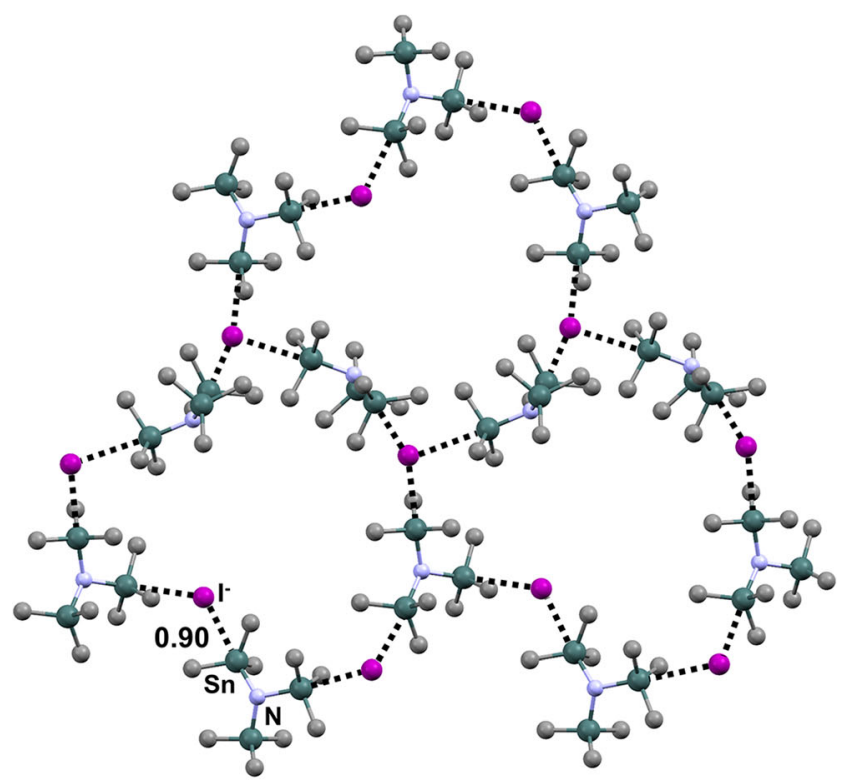

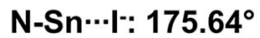

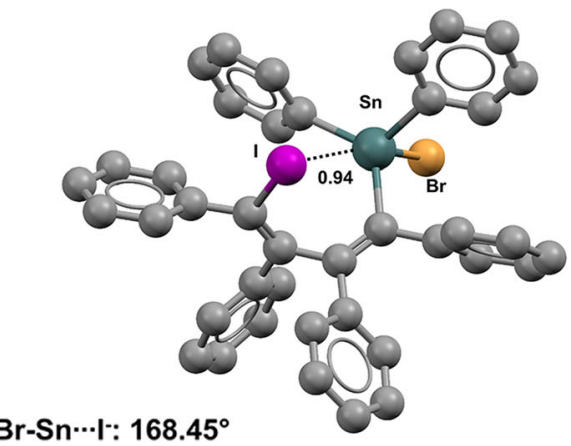

Fig. 26 Ball and stick representations (Mercury 3.9) of the conformation adopted by bromo(4-iodo-1,2,3,4-tetraphenyl-1,3-butadienyl)diphenyltin (SICSOM, bottom) and the network formed by tris(trimethylstannyl)ammonium iodide (RONDAZ, top). One layer of RONDAZ is presented, and hydrogen atoms have been omitted for clarity. TBs are depicted as black dotted lines; Nc values are shown close to the respective interactions. Color code: gray carbon, purple iodine, brown bromine, light blue nitrogen, dark teal tin 
This is the case in the steroid derivative $3 \beta$-(bromodimethylstannyl)-24-nor-5 $\beta$-cholane (refcode MISYAO) [122] (Fig. 25, top), crystals of which include infinitely long $1 \mathrm{D}$ chains assembled via $\mathrm{Br}-\mathrm{Sn} \cdots \mathrm{Br}$.

The covalent bond pathway connecting iodine and tin in (8-iodo-1-naphthyl)trimethyltin (refcode AQIVUS) [123] is reminiscent of that connecting bromine and tin in VEKKUT, and this translates into a supramolecular similarity between the $\mathrm{C}-\mathrm{Sn} \cdots \mathrm{I}$ TB in the former compound and the $\mathrm{Cl}-\mathrm{Sn} \cdots \mathrm{Br}$ TB in the latter. In the crystal structure of bromo(4-iodo1,2,3,4-tetraphenyl-1,3-butadienyl)diphenyltin (refcode SICSOM) (Fig. 26, bottom) [124], the iodine atom acts as the TB acceptor and approaches tin - the TB donor-along the extension of the $\mathrm{Br}-\mathrm{Sn}$ bond $(\mathrm{Nc}=0.94$; the $\mathrm{Br}-\mathrm{Sn} \cdots \mathrm{I}$ angle is $168.95^{\circ}$ ). This pattern is consistent with the fact that the most positive $\sigma$-hole on tin is expected to occur at this position, as bromine is more electron-withdrawing than the other atoms bound to tin. Finally, the $\mathrm{Sn} \cdots \mathrm{I}$ interactions present in crystals of tris(trimethylstannyl)ammonium iodide (refcode RONDAZ) [125] provide a nice example of chargeassisted TB. The existence of this type of TB further highlights the similarities of the different subsets of $\sigma$-hole interactions, as charge-assisted XBs [126] and charge-assisted PBs [31] have already been observed. Specifically, two crystallographically independent salt units are present in the crystal of RONDAZ; in both of these units, the tris(trimethylstannyl)ammonium cations act as tridentate TB donors and the iodide anion as a tridentate TB acceptor, and 3D networks are formed (one 3D network is shown in Fig. 26, top).

\section{Conclusions}

In this paper, we have reported the results of an analysis of the CSD that aimed to identify crystal structures of organic derivatives of germanium and tin in which these two elements form close contacts with lone-pair-possessing atoms.

We focused our attention on close contacts where oxygen, nitrogen, and halogens were the lone-pair-possessing atoms, as a wide range of examples of those close contacts were found in the CSD. However, it may be worth mentioning that other heteroatoms (e.g., sulfur [127-129] and phosphorus [130-132]) also form similar interactions. Ether and carbonyl oxygens as well as amine, pyridine, and cyano nitrogens can all be involved in such interactions, and the geometries observed indicate that the lone pair of the heteroatom is directed towards the germanium/tin atom independent of the hybridization of the oxygen/nitrogen atom (which can be $s p^{3}, s p^{2}$, or $s p$ ). Close contacts are formed by derivatives in which germanium and tin atoms bear four carbon residues or where there are halogen, oxygen, sulfur, or nitrogen substituents instead of one, two, or three of those carbon residues. Regardless of the nature and hybridization state of the lone-pair-possessing atom, and independent of the nature of the residues that are covalently bound to germanium and tin, the close contacts are preferentially formed along the extensions of the covalent bonds that germanium and tin form with strongly electronwithdrawing residues. Moreover, the more electronwithdrawing the residue bound to germanium/tin, the closer the interaction along the extension of that bond.

All of these features are typical of $\sigma$-hole interactions, so we propose that the close contacts described in this review should be termed tetrel bonds. Tetravalent germanium and tin atoms have a tetrahedral geometry. When these atoms form one or two close contacts with lone-pair-possessing atoms, the surrounding geometry tends to change to a trigonal bipyramidal or octahedral geometry, respectively. These changes can be explained as being due to $s p^{3} \rightarrow d s p^{3}$ or $s p^{3} \rightarrow d^{2} s p^{3}$ rehybridization at the tetrels. They can also be rationalized by invoking the presence of a tetrel bond [133] — an attractive interaction between a lone pair and a positive $\sigma$-hole along the extension of a covalent bond formed by the tetrel. The presence of $\sigma$-holes on all four tetrels is widely supported by modeling [38-42], and is also in accord with the experimentally determined geometric features of the interactions discussed in this review. The rationale for tetrel bonding is congruent with the other alternative explanations mentioned above. However, it may offer the additional advantage that these interactions of group 14 elements can be considered to be analogous to similar interactions that occur when groups 15-18 elements function as electrophilic sites.

The examined dataset is too limited to be able to draw general conclusions, but it seems to suggest that the deviation of a tetrel bond from the extension of the relevant covalent bond to a germanium or tin atom is usually smaller than the corresponding deviations for most PBs and CBs [31]. This is consistent with theoretical calculations which show that the region of most positive electrostatic potential opposite to a covalent bond deviates from the extension of the bond to the greatest extent in pnictogen derivatives and to the least extent in tetrel derivatives [134, 135]. The greater linearity of TBs may be related to the fact that the electronic asymmetry generated around germanium and tin atoms by the four residues bonded to them is usually smaller than the electronic asymmetry generated around pnictogen and chalcogen atoms by the residues bonded to them and their lone pair(s) [136].

It also seems that steric congestion around the tetrel atoms studied in this paper plays an influential role in tetrel bond formation; such steric congestion may even prevent tetrel bond formation. For instance, tetrakis(2-fluorobenzyl)tin (refcode VULSOM) forms four intramolecular TBs, whereas its tetrakis(2-chlorobenzyl) analog (refcode CEWGEQ) forms three intramolecular TBs; also, methyltris((2methoxymethyl)phenyl)germane (refcode IMUTEP) forms 
one TB, while its phenyltris((2-methoxymethyl)phenyl) ana$\log$ (IMUTIT) does not form a TB.

In conclusion, the crystal structures discussed in this paper provide reliable experimental evidence that the electrophilicity of germanium and tin in some organic derivatives can be high enough that the tetrel bonds formed with a lone-pairpossessing atom help to determine the structure in crystalline solids of those derivatives. We have shown that intra- and intermolecular tetrel bonds can be found in crystals, and that these interactions can influence the preferred conformation of a molecule and/or the network of intermolecular interactions in the crystal lattice. Tetrel bonds appear to be sufficiently reliable that they could prove useful tools in crystal engineering.

Acknowledgements The authors are pleased to recognize the seminal role of Prof. Dr. Peter Politzer in understanding the interactions discussed in this paper as well as sister interactions, all of which are now grouped together under the term " $\sigma$-hole bonds." The authors are also grateful to Prof. Politzer for fruitful discussions and collaborations regarding this topic.

Open Access This article is distributed under the terms of the Creative Commons Attribution 4.0 International License (http:// creativecommons.org/licenses/by/4.0/), which permits unrestricted use, distribution, and reproduction in any medium, provided you give appropriate credit to the original author(s) and the source, provide a link to the Creative Commons license, and indicate if changes were made.

\section{References}

1. Scheiner S (2015) Noncovalent forces. Springer, Cham. https:// doi.org/10.1007/978-3-319-14163-3

2. Kollman PA (1977) Noncovalent interactions. Acc Chem Res 10: 365-371. https://doi.org/10.1021/ar50118a003

3. Riley KE, Pitončák M, Jurecčka P, Hobza P (2010) Stabilization and structure calculations for noncovalent interactions in extended molecular systems based on wave function and density functional theories. Chem Rev 110:5023-5063. https://doi.org/10.1021/ cr1000173

4. Arunan E, Desiraju GR, Klein RA et al (2011) Definition of the hydrogen bond (IUPAC recommendations 2011). Pure Appl Chem 83:1637-1641. https://doi.org/10.1351/PAC-REC-10-0102

5. Desiraju GR, Steiner T (2001) The weak hydrogen bond in structural chemistry and biology. Oxford University Press, Oxford. https://doi.org/10.1093/acprof:oso/9780198509707.001.0001

6. Swart M, van der Wijst T, Fonseca Guerra C, Bickelhaupt FM (2007) $\pi-\pi$ stacking tackled with density functional theory. J Mol Model 13:1245-1257. https://doi.org/10.1007/s00894-0070239-y

7. Dougherty DA (2013) The cation $-\pi$ interaction. Acc Chem Res 46:885-893. https://doi.org/10.1021/ar300265y

8. Schottel BL, Chifotides HT, Dunbar KR (2008) Anion- $\pi$ interactions. Chem Soc Rev 37:68-83. https://doi.org/10.1039/b614208g

9. Jiang XF, Hau FKW, Sun QF, SY Y, Yam VWW (2014) From

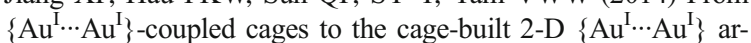
rays: $\mathrm{Au}^{\mathrm{I}} \cdots \mathrm{Au}^{\mathrm{I}}$ bonding interaction driven self-assembly and their
$\mathrm{Ag}^{\mathrm{I}}$ sensing and photo-switchable behavior. J Am Chem Soc 136: 10921-10929. https://doi.org/10.1021/ja502295c

10. Cavallo G, Metrangolo P, Milani R et al (2016) The halogen bond. Chem Rev 116:2478-2601. https://doi.org/10.1021/acs.chemrev. 5 b00484

11. Politzer P, Murray JS, Clark T (2014) $\sigma$-Hole bonding: a physical interpretation. Top Curr Chem 358:19-42. https://doi.org/10. $1007 / 128 \quad 2014568$

12. Clark T, Hennemann M, Murray JS, Politzer P (2007) Halogen bonding: the $\sigma$-hole. J Mol Model 13:291-296. https://doi.org/10. 1007/s00894-006-0130-2

13. Murray JS, Lane P, Politzer P (2009) Expansion of the $\sigma$-hole concept. J Mol Model 15:723-729. https://doi.org/10.1007/ s00894-008-0386-9

14. Murray JS, Lane P, Clark T, Politzer P (2007) $\sigma$-Hole bonding: molecules containing group VI atoms. J Mol Model 13:10331038. https://doi.org/10.1007/s00894-007-0225-4

15. Murray JS, Lane P, Politzer P (2007) A predicted new type of directional noncovalent interaction. Int J Quantum Chem 107: 2286-2292

16. Brinck T, Murray JS, Politzer P (1992) Surface electrostatic potentials of halogenated methanes as indicators of directional intermolecular interactions. Int J Quantum Chem 44:57-64. https://doi. org/10.1002/qua.560440709

17. Brinck T, Murray JS, Politzer P (1993) Molecular surface electrostatic potentials and local ionization energies of group V-VII hydrides and their anions: relationships for aqueous and gas-phase acidities. Int J Quantum Chem 48:73-88. https://doi.org/10.1002/ qua.560480202

18. Politzer P, Murray JS, Clark T (2013) Halogen bonding and other $\sigma$-hole interactions: a perspective. Phys Chem Chem Phys 15: 11178-11189. https://doi.org/10.1039/C3CP00054K

19. Wang H, Wang W, Jin WJ (2016) $\sigma$-hole bond vs $\pi$-hole bond: a comparison based on halogen bond. Chem Rev 116:5072-5104. https://doi.org/10.1021/acs.chemrev.5b00527

20. Bauzá A, Mooibroek TJ, Frontera A (2015) The bright future of unconventional $\sigma / \pi$-hole interactions. ChemPhysChem 16:24962517. https://doi.org/10.1002/cphc. 201500314

21. Politzer P, Murray JS, Clark T (2013) Halogen bonding and other $\sigma$-hole interactions: a perspective. Phys Chem Chem Phys 15: 11178. https://doi.org/10.1039/c3cp00054k

22. Cavallo G, Metrangolo P, Pilati T et al (2014) Naming interactions from the electrophilic site. Cryst Growth Des 14:2697-2702. https://doi.org/10.1021/cg5001717

23. Terraneo G, Resnati G (2017) Bonding matters. Cryst Growth Des 17:1439-1440. https://doi.org/10.1021/acs.cgd.7b00309

24. Metrangolo P, Pilati T, Resnati G, Stevenazzi A (2003) Halogen bonding driven self-assembly of fluorocarbons and hydrocarbons. Curr Opin Colloid Interface Sci 8:215-222. https://doi.org/10. 1016/S1359-0294(03)00055-4

25. Wang W, Ji B, Zhang Y (2009) Chalcogen bond: a sister noncovalent bond to halogen bond. J Phys Chem A 113:81328135. https://doi.org/10.1021/jp904128b

26. Fick RJ, Kroner GM, Nepal B et al (2016) Sulfur-oxygen chalcogen bonding mediates AdoMet recognition in the lysine methyltransferase SET7/9. ACS Chem Biol 11:748-754. https://doi.org/ 10.1021/acschembio.5b00852

27. Nayak SK, Kumar V, Murray JS et al (2017) Fluorination promotes chalcogen bonding in crystalline solids. CrystEngComm 19:4955-4959. https://doi.org/10.1039/C7CE01070B

28. Wonner P, Vogel L, Düser M et al (2017) Carbon-halogen bond activation by selenium-based chalcogen bonding. Angew Chem Int Ed 12009-12012. https://doi.org/10.1002/anie.201704816

29. Legon AC (2017) Tetrel, pnictogen and chalcogen bonds identified in the gas phase before they had names: a systematic look at 
non-covalent interactions. Phys Chem Chem Phys 19:1488414896. https://doi.org/10.1039/C7CP02518A

30. Scheiner S (2013) The pnicogen bond: its relation to hydrogen, halogen, and other noncovalent bonds. Acc Chem Res 46:280 288. https://doi.org/10.1021/ar3001316

31. Scilabra P, Terraneo G, Resnati G (2017) Fluorinated elements of group 15 as pnictogen bond donor sites. J Fluor Chem 203:62-74. https://doi.org/10.1016/j.jfluchem.2017.10.002

32. DeBackere JR, Bortolus MR, Schrobilgen GJ (2016) Synthesis and characterization of $[\mathrm{XeOXe}]^{2+}$ in the adduct-cation salt, $\left[\mathrm{CH}_{3} \mathrm{CN} \cdots \mathrm{XeOXe} \cdots \mathrm{NCCH}_{3}\right]\left[\mathrm{AsF}_{6}\right]_{2}$. Angew Chem Int Ed 55: 11917-11920. https://doi.org/10.1002/anie.201606851

33. Grabowski SJ (2014) Tetrel bond- $\sigma$-hole bond as a preliminary stage of the SN2 reaction. Phys Chem Chem Phys 16:1824-1834. https://doi.org/10.1039/c3cp53369g

34. Jonsson B, Karlstrom G, Wennerstrom, H (1975) Ab initio molecular orbital calculations on the water-carbon dioxide system: molecular complexes. Chem Phys Lett 30:58-59. https://doi.org/10. 1016/0009-2614(75)85497-2

35. Peterson KI, Klemperer W (1984) Structure and internal rotation of $\mathrm{H}_{2} \mathrm{O}-\mathrm{CO}_{2}, \mathrm{HDO}-\mathrm{CO}_{2}$, and $\mathrm{D}_{2} \mathrm{O}-\mathrm{CO}_{2}$ van der Waals complexes. J Chem Phys 80:2439-2445. https://doi.org/10.1063/1. 446993

36. Peng YP, Sharpe SW, Shin SK, Wittig C, Beaudet RA (1992) Infrared spectroscopy of $\mathrm{CO}_{2}-\mathrm{D}(\mathrm{H}) \mathrm{Br}$ complex: molecular structure and its reliability. J Chem Phys 97:5392-5402. https://doi.org/ 10.1063/1.463799

37. Leopold KR, Fraser GT, Klemperer W (1984) Rotational spectrum and structure of the complex $\mathrm{HCN}-\mathrm{CO}_{2}$. J Chem Phys 80: 1039-1046. https://doi.org/10.1063/1.446830

38. Mani D, Arunan E (2013) The $\mathrm{X}-\mathrm{C} \cdots \mathrm{Y}(\mathrm{X}=\mathrm{O} / \mathrm{F}, \mathrm{Y}=\mathrm{O} / \mathrm{S} / \mathrm{F} / \mathrm{Cl} /$ $\mathrm{Br} / \mathrm{N} / \mathrm{P}$ ) "carbon bond" and hydrophobic interactions. Phys Chem Chem Phys 15:14377-14383. https://doi.org/10.1039/c3cp51658j

39. Bauzá A, Mooibroek TJ, Frontera A (2013) Tetrel-bonding interaction: rediscovered supramolecular force? Angew Chem Int Ed 52:12317-12321. https://doi.org/10.1002/anie.201306501

40. Liu M, Li Q, Scheiner S (2017) Comparison of tetrel bonds in neutral and protonated complexes of pyridine $\mathrm{TF}_{3}$ and furan $\mathrm{TF}_{3}(\mathrm{~T}$ $=\mathrm{C}, \mathrm{Si}$, and $\mathrm{Ge}$ ) with $\mathrm{NH}_{3}$. Phys Chem Chem Phys 19:55505559. https://doi.org/10.1039/C6CP07531B

41. Alkorta I, Rozas I, Elguero J (2001) Molecular complexes between silicon derivatives and electron-rich groups. J Phys Chem A 105: 743-749. https://doi.org/10.1021/jp002808b

42. Grabowski SJ (2017) Lewis acid properties of tetrel tetrafluorides - the coincidence of the $\sigma$-hole concept with the QTAIM approach. Crystals 7:43. https://doi.org/10.3390/cryst7020043

43. Southern SA, Bryce DL (2015) NMR investigations of noncovalent carbon tetrel bonds. Computational assessment and initial experimental observation. J Phys Chem A 119:1189111899. https://doi.org/10.1021/acs.jpca.5b10848

44. Mahmoudi G, Bauzá A, Frontera A (2016) Concurrent agostic and tetrel bonding interactions in lead(II) complexes with an isonicotinohydrazide based ligand and several anions. Dalton Trans 45:4965-4969. https://doi.org/10.1039/c6dt00131a

45. Cheng F, Hector AL, Levason W et al (2009) Preparation and structure of the unique silicon(IV) cation $\left[\mathrm{SiF}_{3}\left(\mathrm{Me}_{3} \mathrm{tacn}\right)\right]^{+}$. Chem Commun 1334-1336. https://doi.org/10.1039/b822236c

46. Bondi A (1964) Van der Waals volumes and radii. J Phys Chem 68:441-451. https://doi.org/10.1021/j100785a 001

47. Batsanov SS (2001) Van der Waals radii of elements. Inorg Mater 37:871-885. https://doi.org/10.1023/A:1011625728803

48. Jambor R, Dostál L, Růžička A, Císařová I, Brus J, Holčapek M, Holeček J (2002) Organotin(IV) derivatives of some O,C,O-chelating ligands. Organometallics 21:3996-4004. https://doi.org/10. 1021/om020361i
49. Dostál L, Jambor R, Růžička A et al (2007) Organotin(IV) derivatives of some O,C,O-chelating ligands. Part 2. Organometallics 26:6312-6319. https://doi.org/10.1021/om700576n

50. Scheiner S (2017) Systematic elucidation of factors that influence the strength of tetrel bonds. J Phys Chem A 121:5561-5568. https://doi.org/10.1021/acs.jpca.7b05300

51. Sugiyama Y, Matsumoto T, Yamamoto H et al (2003) Synthesis, solid-state and solution structures of tris [(2methoxymethyl)phenyl]germanes with a substituent on germanium. Tetrahedron 59:8689-8696. https://doi.org/10.1016/j.tet. 2003.09.053

52. Shindo M, Matsumoto K, Shishido K (2007) Hyperconjugative effect of C-Ge bonds: synthesis of multisubstituted alkenylgermanes via torquoselective olefination of acylgermanes with ynolates. Tetrahedron 63:4271-4277. https://doi.org/10. 1016/j.tet.2007.03.048

53. Jousseaume B, Villeneuve PM, Driiger Roller S, Chezeau JM (1988) Unique tin-oxygen coordination bond in a pentacoordinated tetraorganotin compound. First confirmation by X-ray crystal structure of (2-carbomethoxy-1,4cyclohexadien-1-yl) trimethyltin. J Organomet Chem 349:C1C3. https://doi.org/10.1016/0022-328X(88)80459-5

54. Beak P, Lee WK (1993) $\alpha$-Lithioamine synthetic equivalents: syntheses of diastereoisomers from Boc derivatives of cyclic amines. J Org Chem 58:1109-1117. https://doi.org/10.1021/ jo00057a024

55. Cintrat JC, Léat-Crest V, Parrain JL, et al (2004) Identification of chiral cis- and trans-2-stannyloxazolidines by their NMR spectra and solid-state structures. Eur J Org Chem 4268-4279. https://doi. org/10.1002/ejoc.200400203

56. Gurkova SN, Gusev AI, Alekseev NV, Gar TK, Viktorov NA (1984) Intramolecular interactions in germanium compounds. Crystal and molecular structures of the $N, N^{\prime}$-dimethylamide of 2methyl-3-(trichlorogermyl) propionic acid and 1-(1trichlorogermyl) pyrrolid-2-one. J Struct Chem 25:825-828

57. Deka DC, Helliwell M, Thomas EJ (2001) Synthesis of chiral organotin reagents: synthesis and X-ray crystal structures of bicyclo[2.2.1] heptan-2-yl(diphenyl)tin chlorides with cis-disposed nitrogen containing substituents. Tetrahedron 57:1001710026. https://doi.org/10.1016/S0040-4020(01)01035-3

58. Tretyakov EV, Mareev AV, Demina MM et al (2009) Silyl- and germylpropynals in the synthesis of azolyl-substituted 2imidazoline 3-oxide 1-oxyls. Russ Chem Bull. 58:1915-1920. https://doi.org/10.1007/s11172-009-0261-6

59. Gurkova SN, Gusev AI, Alekseev NV, Gar TK, Viktorov NA (1984) Intramolecular interactions in germanium compounds. Crystal and molecular structure of 1,3-diphenyl-3-methyl-3(trichlorogermyl)-butan-1-one. J Struct Chem 25:829-831

60. Wang LB (2007) ( $\mu-2,2^{\prime}$-Biquinolinyl-4,4'-dicarboxylato- $\kappa^{2} O$ : $\left.O^{\prime}\right)$ bis[(dimethylformamide-k $\left.O\right)$ triphenyltin(IV)]. Acta Crystallogr E 63:m1883-m1883. https://doi.org/10.1107/ S1600536807028048

61. Lorberth J, Shin S, Donath H, Wacadlo S, Massa W (1991) Metalorganic diazoalkanes: XX. Crystal structure of trimethyltin diazoacetic ester, $\mathrm{Me}_{3} \mathrm{SnC}\left(\mathrm{N}_{2} \mathrm{CO}_{2}\right.$ Et. J Organomet Chem 407: 167-171

62. Lukevics E, Arsenyan P, Belyakov S et al (1999) Cycloaddition reactions of nitrile oxides to silyl- and germyl-substituted thiophene-1,1-dioxides. Organometallics 18:3187-3193. https:/doi. org/10.1021/om9902129

63. Chuprunov EV, Stolyarova NE, Shcherbakov VI, Tarkhova TN (1988) Crystal structure of $N$-triethylstannylsuccinimide. J Struct Chem 28:797-799

64. Jaray O, Pritzkow H, Jander J (1977) X-ray structural analysis of organic $\mathrm{N}-\mathrm{Br}$ compounds for making visible general structure elements of bromamines. Z Naturforsch 32b:1416-1420 
65. Adama MS, D-F D, Zhu D-S, Xu L (2011) The one-dimensional chain: synthesis, crystal structure and biological activities of tricyclohexyl tin carboxylates. Chin J Struct Chem 27:107-113

66. Kuang D-Z, Zhu X-M, Feng Y-L, Zhang F-X, Yu J-X, Jiang W-J, Tan Y-X, Zhang JZ (2015) Syntheses, crystal structures and biological activities of bis(tricyclohexyltin)dicarboxylates with macrocyclic building 2D network. Chin J Struct Chem 31:2044-2050

67. Ma C, Wang Q, Zhang R (2008) Self-assembly of triorganotin complexes: syntheses, characterization, and crystal structures of dinuclear, 1D polymeric chain, and 2D network polymers containing chiral (+)-(1R,3S)-camphoric acid and meso-cis-4-cyclohexene-1,2-dicarboxylic acid ligands. Eur J Inorg Chem 2008:19261934. https://doi.org/10.1002/ejic.200701211

68. Uehara K, Nakao H, Kawamoto R et al (2006) 2D-grid layered pdbased cationic infinite coordination polymer/polyoxometalate crystal with hydrophilic sorption. Inorg Chem 45:9448-9453. https://doi.org/10.1021/ic061393r

69. Taylor P, Poll E, Olbrich F, Fischer RD (2014) $\left[\mathrm{Sn}_{2}\left(\mathrm{H}_{2} \mathrm{O}\right)_{2} \mathrm{Br}_{2}\left(\mathrm{CH}_{3}\right)_{4}\left\{\mu-\left(\mathrm{CH}_{2}\right)_{3}\right\} \cdot 2\right.$ bpy]: a layered, hetero bimolecular composite (bpy=2,2-bipyridine). Supramol Chem 10: 2014. https://doi.org/10.1080/10610270290029344

70. Reeske G, Schürmann M, Costisella B, Jurkschat K (2005) Organotin-substituted crown ethers for ditopic complexation of anions and cations. Eur J Inorg Chem 2881-2887. https://doi. org/10.1002/ejic.200500191

71. Mandolesi S, Studentkowski M, Preut H, Mitchell T (2001) A 1:1 adduct between 2,2-bis(chlorodimethylstannyl)propane and dimethyl sulfoxide. Acta Crystallogr E 57:m543-m544. https:// doi.org/10.1107/S1600536801017603

72. Zhu FC, Shao PX, Yao XK et al (1990) Stereochemistry and crystal structures of triphenyltin chloride complexes with bis(phenylsulfinyl)ethane. Inorg Chim Acta 171:85-88. https:// doi.org/10.1016/S0020-1693(00)84669-1

73. Kumar S, Shadab SM, Idrees M (2009) Chlorido(dimethyl sulfoxide-kO)triphenyltin(IV). Acta Crystallogr E 65:m1602-m1603. https://doi.org/10.1107/S1600536809048090

74. Howie RA, Wardell JL (1994) Structures of $\mathrm{Ph}_{3} \mathrm{SnCH}_{2} \mathrm{CH}_{2} \mathrm{CH}_{2} \mathrm{~S} \mathrm{O}_{2} \mathrm{C}_{6} \mathrm{H}_{4} \mathrm{Me}-\mathrm{p}$ and $\mathrm{IPh}_{2} \mathrm{SnCH}_{2} \mathrm{CH}_{2} \mathrm{CH}_{2} \mathrm{SO}_{2} \mathrm{C}_{6} \mathrm{H}_{4} \mathrm{Me}$-p. Main Group Met Chem. 17:571-582. https://doi.org/10.1515/MGMC.1994.17.8.571

75. Lo KM, Ng SW (2011) Tribenzyl-chlorido(triphenyl-phosphine oxide-KO)tin(IV). Acta Crystallogr E 67:112-122. https://doi. org/10.1107/S160053681101957X

76. Lo KM, Ng SW (2004) [Chlorobis( $p$-chlorophenyl)(p-tolyl)tin]$\mu$-1,2-bis(diphenylphosphoryl)ethane- $\kappa^{2} O: O^{\prime}$-[bromobis $(p$ chlorophenyl)(p-tolyl)tin]. Acta Crystallogr E 60:m717-m719. https://doi.org/10.1107/S1600536804010219

77. Preut H, Godry B, Mitchell TN (1992) [2(Bromodimethylstannyl)ethyl]diphenylphosphine sulfide. Acta Crystallogr Sect C 48:1491-1493. https://doi.org/10.1107/ S0108270191014750

78. Shariatinia Z, Mirhosseini Mousavi HS, Bereciartua PJ, Dusek M (2013) Structures of a novel phosphoric triamide and its organotin(IV) complex. J Organomet Chem 745-746:432-438. https://doi.org/10.1016/j.jorganchem.2013.08.003

79. Jurkschat K, Tzschach A, Meunierpiret J (1986) Synthesis, crystal and molecular structure of 1-AZA-5-STANNA-5methyltricyclo[3.3.3. $0^{1,5}$ ] undecane. Evidence for a transannular donor-acceptor interaction in a tetraorganotin compound. J Organomet Chem 315:45-49. https://doi.org/10.1016/0022328X(86)80409-0

80. Jurkschat K, Hesselbarth F, Dargatz M, Lehmann J, Kleinpeter E, Tzschach A, Meunierpiret J (1990) 1,2-Bis(organostannyl)ethanes as powerful bidentate Lewis acids. Crystal structures of $\left(\mathrm{Ph}_{2} \mathrm{C} 1 \mathrm{SnCH}\right)_{2} \cdots\left(\mathrm{Me}_{2} \mathrm{~N}\right)_{2} \mathrm{PO}$ a n d
$\left[\mathrm{Ph}_{3} \mathrm{P}=\mathrm{N}=\mathrm{PPh}_{3}\right]\left[\left(\mathrm{Ph}_{2} \mathrm{ClSnCH}_{2}\right)_{2} \cdots \mathrm{Cl}\right]$. J Organomet Chem 388: 259-271. https://doi.org/10.1016/0022-328X(90)85373-7

81. Lo KM, Ibrahim AR, Chantrapromma S, Fun HK, Ng SW (2001) C r y t a 1 s t r c t u r of bromotri ( $p$ tolyl)tinhexamethylphosphoramide. Main Group Met Chem 24: 301-302. https://doi.org/10.1515/MGMC.2001.24.5.301

82. Breliere C, Carre F, Corriu RJP, Royo G (1988) Synthesis and structures of hypervalent species of silicon and germanium: toward heptacoordination? Organometallics 7:1006-1008. https:// doi.org/10.1021/om00094a034

83. Wingerter S, Pfeiffer M, Stey T et al (2001) The iminophosphorane $\mathrm{Ph}_{3} \mathrm{P}=\mathrm{NSiMe}_{3}$ as a synthon for $\mathrm{M}-\mathrm{C}_{\text {aryl }} \sigma$ bonds $(\mathrm{M}=\mathrm{In}, \mathrm{Fe}, \mathrm{Ge})$ implementing imino sidearm donation. Organometallics 20:2730-2735. https://doi.org/10.1021/ om0009738

84. Gurkova SN, Gusev AI, Alekseev NV, Segel'man RI, Gar TK, Khromova NY (1983) Crystal and molecular structure of 1-(tertbutyl)germatrane. J Struct Chem 24:155-157. https://doi.org/10. 1021/ic50138a020

85. Gurkova SN, Gusev AI, Alekseev NV, Segel'man RI, Gar TK, Khromova NYu (1983) Crystal and molecular structure of 1bromogermatrane. J Struct Chem 24:238-241. https://doi.org/10. 1007/BF00747386

86. Gurkova SN, Gusev AI, Alekseev NV, Segel'man RI, Gar TK, Khromova NY (1981) Crystal and molecular structure of Iodomethylgermatrane. J Struct Chem 22:461-462

87. Gurkova SN, Gusev AI, Alekseev NV, Gar TK, Khromova NY (1981) Crystal and molecular structure of 1-methyl-2carbagermatrane. J Struct Chem 22:924-926

88. Gurkova SN, Gusev AI, Alekseev NV, Gar TK, Viktorov NA (1985) Crystal and molecular structure of 1-(germatranyl)-1-(2pyrrolidonyl)ethane. J Struct Chem 26:124-127

89. Shutov PL, Sorokin DA, Karlov SS et al (2003) Azametallatranes of group 14 elements. Syntheses and X-ray studies. Organometallics 22:516-522. https://doi.org/10.1021/ om020708h

90. Karlov SS, Lermontova EK, Zabalov MV et al (2005) Synthesis, $\mathrm{X}$-ray diffraction studies, and DFT calculations on hexacoordinated germanium derivatives: the case of germaspirobis(ocanes). Inorg Chem 44:4879-4886. https://doi. org/10.1021/ic048165m

91. Jurkschat K, Kolb U, Dräger M, Dargatz M (1995) Unusual hexacoordination in a triorganotin fluoride supported by intermolecular hydrogen bonds. Crystal and molecular structures of 1-aza5-stanna-5-halogenotricyclo[3.3.3.01.5] undecanes $\mathrm{N}\left(\mathrm{CH}_{2} \mathrm{CH}_{2} \mathrm{CH}_{2}\right)_{3} \mathrm{SnF} \cdot \mathrm{H}_{2} \mathrm{O}$ and $\mathrm{N}\left(\mathrm{CH}_{2} \mathrm{CH}_{2} \mathrm{CH}_{2}\right)_{3} \mathrm{SnX}(\mathrm{X}=\mathrm{Cl}$, Br, I). Organometallics 14:2827-2834. https://doi.org/10.1021/ om00006a031

92. Jurkschat K, Tzschach A (1985) Crystal and molecular structure of 1-aza-5-stanna-5-chlorotricyclo[3.3.3] undecane, a 2,8,9tricarbastannatrane. J Organomet Chem 290:285-289

93. Turek J, Padělková Z, Černošek Z et al (2009) C,N-chelated hexaorganodistannanes, and triorganotin(IV) hydrides and cyclopentadienides. J Organomet Chem 694:3000-3007. https:// doi.org/10.1016/j.jorganchem.2009.04.043

94. Růžička A, Padělková Z, Švec P et al (2013) Quest for triorganotin(IV) compounds containing three $\mathrm{C}, \mathrm{N}-$ and $\mathrm{N}, \mathrm{C}, \mathrm{N}-$ chelating ligands. J Organomet Chem 732:47-57. https://doi. org/10.1016/j.jorganchem.2013.02.018

95. Kawachi A, Tanaka Y, Tamao K (1999) Synthesis and structures of a series of $\mathrm{Ge}-\mathrm{M}(\mathrm{M}=\mathrm{C}, \mathrm{Si}$, and $\mathrm{Sn})$ compounds derived from germyllithium containing three 2-(dimethylamino)phenyl groups on germanium. J Organomet Chem 590:15-24. https://doi.org/10. 1016/S0022-328X(99)00386-1

96. Novák P, Císařová I, Jambor R et al (2004) Coordination behaviour of the 2-(N,N-dimethylaminomethyl)phenyl ligand towards 
the di-t-butylchlorotin(IV) moiety. Appl Organomet Chem 18: 241-243. https://doi.org/10.1002/aoc.615

97. Pichler J, Torvisco A, Bottke P et al (2014) Novel amino propyl substituted organo tin compounds. Can J Chem 92:565-573. https://doi.org/10.1139/cjc-2013-0504

98. Zhu C, Yang L, Li D et al (2011) Synthesis, characterization, crystal structure and antitumor activity of organotin(IV) compounds bearing ferrocenecarboxylic acid. Inorg Chim Acta 375: 150-157. https://doi.org/10.1016/j.ica.2011.04.049

99. Winkelhaus D, Neumann B, Stammler H-G, Mitzel NW (2012) Bis(tetrafluorophenyl)borane. Dalton Trans 41:8609. https://doi. org/10.1039/c2dt30924f

100. Hong M, Geng H, Niu M, Wang F, Li D, Liu J, Yin H (2014) Organotin(IV) complexes derived from Schiff base $N^{\prime}-[(1 E)-(2-$ hydroxy-3-methoxyphenyl)methylidene]pyridine-3carbohydrazone: synthesis, in vitro cytotoxicities and DNA/BSA interaction. Eur J Med Chem 86:550-561. https://doi.org/10.1016/ j.jorganchem.2015.12.041

101. Gupta AN, Kumar V, Singh V et al (2015) Influence of functionalities on the structure and luminescent properties of organotin(IV) dithiocarbamate complexes. J Organomet Chem 787:65-72. https://doi.org/10.1016/j.jorganchem.2015.03.034

102. Feng YL, Yu J-X, Kuang D-Z, Yin D-L, Zhang F-X, Wang J-Q, liu M-Q (2011) Synthesis, crystal structure and quantum chemistry of tricyclohexyl tin pyridine-4-carboxylate polymer. Chin J Inorg Chem. 27:1793-1797

103. Chandrasekhar V, Mohapatra C (2013) 2D-coordination polymer containing interconnected 82-membered organotin macrocycles. Cryst Growth Des 13:4655-4658. https://doi.org/10.1021/ cg401363p

104. Ma CL, Han YF, Li DC (2004) Synthesis and crystal structures of diorganotin dicyanoethylene-1,2-dithiolate compounds and their derivatives with 4,4'-Bipy or Phen. Polyhedron 23:1207-1216. https://doi.org/10.1016/j.poly.2004.01.019

105. Bajue SA, Bramwell FB, Charles M et al (1992) Crystal and molecular structures of the adducts of tri- $p$-tolyltin chloride, bromide and iodide with 4,4'-bipyridine. Inorg Chim Acta 197:83-87. https://doi.org/10.1016/S0020-1693(00)85523-1

106. Avalle P, Harris RK, Hanika-Heidl H, Dieter Fischer R (2004) Magic-angle spinning NMR spectra and re-examined crystal structure of trimethyltin cyanide. Solid State Sci 6:1069-1076. https://doi.org/10.1016/j.solidstatesciences.2004.06.001

107. Konnert JH, Britton D, Chow YM (1972) The crystal structures of the dimethyldicyano compounds of silicon, germanium, tin and lead. Acta Crystallogr B 28:180-187. https://doi.org/10.1107/ S0567740872002043

108. Kuang DZ, Jiang JP, Feng YL, Zhang FX, Wang JQ, Luo JM (2008) Synthesis and crystal structure of tetra(o-cyanobenzyl)tin. Chin J Struct Chem 27:35-38

109. Švec P, Růžičková Z, Vlasák P et al (2016) Expanding the family of C,N-chelated organotin(IV) pseudohalides: synthesis and structural characterization. J Organomet Chem 801:14-23. https://doi. org/10.1016/j.jorganchem.2015.10.014

110. Coffer PK, Dillon KB, Howard JAK et al (2012) Synthesis and characterisation of selected group 14 derivatives of the 2,5$\left(\mathrm{CF}_{3}\right)_{2} \mathrm{C}_{6} \mathrm{H}_{3}$ (Ar) ligand. Dalton Trans 41:4460-4468. https://doi. org $/ 10.1039 / \mathrm{c} 2 \mathrm{dt} 12369 \mathrm{j}$

111. Brisdon AK, Pritchard RG, Thomas A (2012) Pentafluoropropenyl complexes of mercury, germanium, tin, and lead derived from $(Z)-\mathrm{CFH}=\mathrm{CFCF}_{3}$ and their use as transfer reagents. Organometallics 31:1341-1348. https://doi.org/10. 1021/om2009843

112. Calogero S, Ganis P, Peruzzo V, Tagliavini G, Valle G (1981) Xray and Mössbauer studies of tricyclohexyltin(IV) halides. The crystal structures of (cyclo- $\left.\mathrm{C}_{6} \mathrm{H}_{11}\right)_{3} \mathrm{SnX}(\mathrm{X}=\mathrm{F}, \mathrm{Br}$ and I). J Organomet Chem 220:11-20
113. Bilayet Hossain M, Lefferts JL, Molloy KC, Van der Helm D, Zuckerman JJ (1979) Crystal and molecular structure of trimethyl-tin chloride at $135 \mathrm{~K}$. Inorg Chim Acta 36:L409-L410

114. Chaudhary P, Bieringer M, Hazendonk P, Gerken M (2015) The structure of trimethyltin fluoride. Dalton Trans 44:19651-19658. https://doi.org/10.1039/C5DT01994J

115. Alcock NW, Sawyer JF (1977) Secondary bonding. Part 2. Crystal and molecular structures of diethyltin dichloride, dibromide, and diiodide. J Chem Soc Dalton Trans 1090-1095

116. Frank W, Reiss GJ, Kuhn D (1994) Trichloromethyltin(IV). Acta Crystallogr C 50:1904-1906. https://doi.org/10.1107/ S010827019400795X

117. Schürmann M, Silvestri A, Ruisi G et al (1999) The structure and dynamics of Cl-substituted tetraphenyl- and tetrabenzyl-tin(IV). J Organomet Chem 584:293-300. https://doi.org/10.1016/S0022328X(99)00166-7

118. Ross JN, Wardell J, Ferguson G, Low JN (1994) Symmetrical tetrasubstituted tin compounds: tetrakis(2-methoxyphenyl)tin and tetrakis(2-methoxybenzyl)tin. Acta Crystallogr C 50:1703-1707. https://doi.org/10.1107/S0108270194006815

119. Zhang FU, Kuang DZ, Feng YL, Wang JQ, JZ Y, Jiang WJ, Zhu XM (2015) Synthesis, crystal structure and properties of the tetra( $o$-fluorobenzyl)tin and the tribenzyltin ferrocenecarboxylate. Chin J Struct Chem 31:1194-1200. https://doi.org/10.11862/ CJIC.2015.157

120. Veith M, Agustin D, Huch V (2002) New synthetic approach and structural characterization of the chloroalkylstannanes $\left(\mathrm{Cl}-\mathrm{CH}_{2}\right)_{n}$ $\mathrm{SnCl}_{4-n}(n=2,4)$ and the hydrolysis product $\left[\left(\mathrm{ClCH}_{2}\right)_{2} \mathrm{Sn}(\mathrm{Cl})-\mathrm{O}-\right.$ $\left.\mathrm{Sn}(\mathrm{Cl})\left(\mathrm{CH}_{2} \mathrm{Cl}\right)_{2}\right]_{2}$. J Organomet Chem 646:138-145. https://doi. org/10.1016/S0022-328X(01)01099-3

121. Lechner ML, Athukorala Arachchige KS, Randall RAM et al (2012) Sterically crowded tin acenaphthenes. Organometallics 31:2922-2930. https://doi.org/10.1021/om201253t

122. Schiesser CH, Skidmore MA, White JM (2001) Stannanes from cholic acid as enantioselective free-radical reducing agents. Aust J Chem 54:199-204. https://doi.org/10.1071/CH01045

123. Meyer N, Sivanathan S, Mohr F (2011) Transfer of organic groups to gold using organotin compounds. J Organomet Chem 696: 1244-1247. https://doi.org/10.1016/jJorganchem.2010.10.060

124. Muchmore CRA, Heeg MJ (1990) Structure of bromo(4-iodo-1,2, 3,4-tetraphenyl-1,3-butadienyl)diphenyltin(IV). Acta Crystallogr C 46:1743-1745. https://doi.org/10.1107/S0108270190003158

125. Hillwig R, Harms K, Dehnicke K, Muller U (1997) Organoelement substituted ammonia salts. Crystal structures of $\left[\mathrm{HN}\left(\mathrm{SnMe}_{3}\right) 3\right] \mathrm{I},\left[\mathrm{H}_{2} \mathrm{~N}\left(\mathrm{SnMe}_{3}\right)_{2}\right]\left[\mathrm{SnMe}_{3} \mathrm{Cl}_{2}\right]$, and [N(AsMe $\left.)_{2}\right]$ Br. Z Anorg Allg Chem 623:676-682. https://doi. org/10.1002/zaac.199762301107

126. Cavallo G, Murray JS, Politzer P et al (2017) Halogen bonding in hypervalent iodine and bromine derivatives: halonium salts. IUCrJ 4:411-419. https://doi.org/10.1107/S2052252517004262

127. Affan MA, Salam MA, Ahmad FB, Hitam RB, White F (2012) Triorganotin(IV) complexes of pyruvic acid-N(4)cyclohexylthiosemicarbazone (HPACT): synthesis, characterization, crystal structure and in vitro antibacterial activity. Polyhedron 33:19-24. https://doi.org/10.1016/j.poly.2011.11.021

128. Jurkschat K, Schmid B, Dybiona M, Baumeister U, Hartung H, Tzschach A (1988) Zur Struktur und Reaktivitat von stannylierten Propylaminen und -sulfiden. Kristall- und Molekulstruktur von Bis ( 3 -dimethyl. chlorostannylpropy 1 )sulfid $\mathrm{S}\left(\mathrm{CH}_{2} \mathrm{CH}_{2} \mathrm{CH}_{2} \mathrm{SnMe}_{2} \mathrm{CI}\right)$. Z Anorg Allg Chem 560:110-118. https://doi.org/10.1002/zaac.19885600113

129. Vargas-Pineda DG, Guardado T, Cervantes-Lee F et al (2010) Intramolecular chalcogen-tin interactions in $[(o-$ $\left.\left.\mathrm{MeEC}_{6} \mathrm{H}_{4}\right) \mathrm{CH}_{2}\right]_{2} \mathrm{SnPh}_{2-n} \mathrm{Cl}_{n}\left(\mathrm{E}=\mathrm{S}, \mathrm{O}, \mathrm{CH}_{2} ; n=0,1,2\right)$ and intermolecular chlorine-tin interactions in the meta- and para- 
methoxy isomers. Inorg Chem 49:960-968. https://doi.org/10. $1021 /$ ic $901800 \mathrm{c}$

130. Seibert M, Merzweiler K, Wagner C, Weichmann H (2002) Synthesis and structural behavior of the P-functional organotin. J Organomet Chem 650:25-36. https://doi.org/10.1016/S0022328X(02)01116-6

131. Hoppe S, Weichmann H, Jurkschat K et al (1995) Synthesis and structural studies of 2-stannyl-substituted ferrocenylmethylamine and -phosphine derivatives 2- $\mathrm{Me}_{2} \mathrm{RSnFcCH}_{2} \mathrm{Y}(\mathrm{R}=\mathrm{Me}, \mathrm{Cl}$; $\left.\mathrm{Y}=\mathrm{NMe}_{2}, \mathrm{PPh}_{2}, \mathrm{P}(\mathrm{O}) \mathrm{Ph}_{2} ; \mathrm{Fc}=\mathrm{C}_{10} \mathrm{H}_{8} \mathrm{Fe}\right) . \mathrm{J}$ Organomet Chem 505:63-72. https://doi.org/10.1016/0022-328X(95)05549-5

132. Baumeister U, Hartung H, Krug A, Merzweiler K, Schulz T, Wagner C, Weichmann H (2000) Ligand behaviour of Pfunctional organotin halides: nickel(II), palladium(II), and
platinum(II) complexes with $\mathrm{Me}_{2}(\mathrm{Cl}) \mathrm{SnCH}_{2} \mathrm{CH}_{2} \mathrm{PPh}_{2}$. Z Anorg Allg Chem 626:2185-2195

133. Politzer P, Murray JS, Lane P, Concha MC (2009) Electrostatically driven complexes of $\mathrm{SiF}_{4}$ with amines. Int J Quantum Chem 109: 3773-3780. https://doi.org/10.1002/qua.22385

134. Scheiner S (2016) Highly selective halide receptors based on chalcogen, pnicogen, and tetrel bonds. Chem Eur J 22:18850-18858. https://doi.org/10.1002/chem.201603891

135. Murray JS, Resnati G, Politzer P (2017) Close contacts and noncovalent interactions in crystals. Faraday Discuss 203:113130. https://doi.org/10.1039/c7fd00062f

136. Politzer P, Murray JS, Clark T, Resnati G (2017) The $\sigma$-hole revisited. Phys Chem Chem Phys 19:32166-32178. https://doi. org/10.1039/C7CP06793C 